\title{
Corruption, Fiscal Policy, and Growth: A Unified Approach
}

\author{
Sugata Ghosh ${ }^{\mathrm{a}}$ and Kyriakos C. Neanidis ${ }^{\mathrm{b}}$ \\ ${ }^{a}$ Department of Economics and Finance, Brunel University, and Centre for Economic \\ Development and Institutions, United Kingdom \\ ${ }^{b}$ Economics, University of Manchester, and \\ Centre for Growth and Business Cycles Research, United Kingdom
}

\begin{abstract}
We study the effects of bureaucratic corruption on fiscal policy and economic growth, where corruption (i) reduces the tax revenue raised from households, (ii) inflates the volume of government spending, and (iii) reduces the productivity of 'effective' government expenditure. We distinguish between the policies pursued by (a) a nonoptimising, and (b) an optimising government. For both cases, corruption leads to higher income tax and inflation rates and a lower level of government spending, thus hindering growth. In the circumstances, an activist government could allocate its resources in attempting to reduce the type of corruption that harms growth the most. Finally, the findings from our unified framework could rationalise the sometimes conflicting empirical evidence on the impact of corruption on growth in the literature.
\end{abstract}

Keywords: Corruption, economic growth, public expenditure and revenue, nonoptimising and optimising government.

JEL classification: D73, E60, O42.

\section{Introduction}

Corruption was deemed "Public Enemy Number One" in developing countries by the World Bank Group President, Jim Yong Kim, on December 19, 2013. One of the key steps identified by Kim to counter this was in "building institutions with greater 
integrity". This clearly underlines the World Bank's awareness of corruption, via the activities of unscrupulous public officials, as a pervasive evil, and of its commitment to fight this menace. In this paper, we explore the channels through which corruption could thrive within a bureaucracy, and investigate the ways in which a government could attempt to offset this via the appropriate use of its policy instruments.

The pernicious effects of corruption on growth are well-acknowledged, although a strand of the literature argues that corruption could have some beneficial effects. ${ }^{2} \mathrm{~A}$ number of questions on the topic of corruption have evolved over the years and evoked genuine interest among academics as well as policymakers, and many of these critical questions centre around the public finance aspects of a government. ${ }^{3}$ How can the impact of corruption via the expenditure and revenue sides of the government budget constraint be captured, and is this sizeable enough to influence the macroeconomy? How do governments design appropriate spending and tax policies to moderate the effects of such corruption? Do the economic outcomes differ significantly when, in the presence of corruption, a government takes an active fiscal stance (by optimally choosing its policy instruments), instead of adjusting its instruments to ensure a balanced budget? In this paper, we provide answers to these types of questions through a unified approach linking bureaucratic corruption, ${ }^{4}$ fiscal policy and growth within an endogenous growth framework, given that such issues have rarely been addressed within the same framework in the related literature.

There is no dearth of studies analyzing corruption within a general equilibrium framework. In early contributions, Barreto (2000) and Ellis and Fender (2006) explain the endogenous presence of corruption by assuming that the government is self-interested,

\footnotetext{
${ }^{1}$ See, for instance, http://www.worldbank.org/en/news/press-release/2013/12/19/corruption-developingcountries-world-bank-group-president-kim. Earlier in 1996, and in the same vein, the former World Bank President, James D. Wolfensohn, had publicly declared corruption as a "cancer".

${ }^{2}$ The efficiency or "speed money" hypothesis (see Leff (1964), Huntington (1968), Lui (1985), etc.) has largely been overturned in the literature by the inefficiency argument of corruption via rent-seeking activities, barriers to innovation, adoption of inefficient technologies, etc. (see, for example, Krueger (1974), Murphy et al. (1991), Acemoglu (1995), Ehrlich and Lui (1999), Hall and Jones (1999), Sarte (2000), and Svensson (2005)).

${ }^{3}$ See Hillman (2004) for an IMF perspective on how corruption makes public finance ineffective in promoting economic development.

${ }^{4}$ Bureaucratic (or "petty") corruption occurs when bureaucrats running the administration are corrupt, as in this paper, and the government is benevolent; while with "grand" corruption, the government itself is corrupt. (See Rose-Ackerman (1999) for a distinction.)
} 
rather than benevolent. In Barreto (2000), the government has a natural monopoly over the provision of public goods, so that in the absence of corruption the public sector provides such goods at the marginal cost, achieving Pareto equilibrium. The author shows that a self-seeking government, with its representatives (the public officials), exploits the monopoly power that it has over the provision of public goods, so that less public goods are provided at higher prices relative to the competitive scenario. The public sector's monopoly profits represent the endogenous level of corruption within the economy, while limitations on the extent of corruption depend on the ability of the private sector to exert control over government activity. ${ }^{5}$ In a similar spirit, Ellis and Fender (2006) introduce endogenous corruption into a variant of the Ramsey model, where a government taxes private producers and uses the resources to either provide public capital or consume them, the latter constituting grand corruption. Due to the introduction of a time lag in the production process of public capital, the detection of corruption is not immediate and provides the government an incentive for appropriating public funds, which in turn gives rise to a level of irreducible corruption in the economy. The predictions accord well with the existing empirical evidence on the links amongst corruption, public investment, and the level and growth rate of output, while they also explain the observed features of the time paths of corruption.

More recently, Ivanyna et al. (2016) use a model to study the interaction among corruption, tax evasion and fiscal policy, all endogenously determined. In the model, the average level of government corruption affects households' willingness to evade taxes and an official's inclination to be corrupt. Tax evasion, in turn, affects corruption by restricting the amount of funds that can be raised by the government. Based on these assumptions, corruption tends to force the tax rate up because corrupt officials want to divert some government revenue earmarked for investment for their own private use, while tax evasion tends to force the tax rate down because evasion lowers the government's ability to raise revenue at higher tax rates. The authors find that when the model is calibrated to match typical tax evasion levels found in developing countries, the net tax rate is significantly higher than in a baseline model with no corruption and

\footnotetext{
${ }^{5}$ Mauro (2004) and Litina and Palivos (2016) extend the idea of endogenous levels of corruption by developing models with multiple self-fulfilling equilibria where different levels of corruption can emerge based on the existence of strategic complementarities.
} 
evasion. The rise in corruption lowers the government revenue that is actually invested in public capital, and the rise in the tax rate reduces private investment and worker productivity. However, the drop is not large, which could explain the difficulty in establishing a statistically significant correlation between corruption and growth in crosscountry studies.

Our analysis complements and is most closely related to two recent contributions, by Myles and Yousefi (2015) and Ivanyna et al. (2015). Myles and Yousefi (2015) explore whether the positive correlation between corruption and inflation, as revealed by cross-section data, can be explained by an optimizing government using seigniorage to compensate for tax revenue lost to corruption. Three forms of corruption are considered: the reduction of effective tax burden, appropriation of tax revenue, and the appropriation of newly produced money. With a government choosing the monetary growth rate to maximize its social welfare function, the authors show that an increase in (any form of) corruption can raise monetary growth, the level of seigniorage, and subsequently the rate of inflation. Similarly focused on fiscal considerations, Ivanyna et al. (2015) study how the presence of corruption and tax evasion affects the way a country's fiscal (especially public debt) policy is conducted. The authors focus on grand corruption and show that even when the other fundamentals of the (corruption-free) economy suggest that the optimal public debt level should be zero, the presence of corruption creates an incentive for public officials to enlarge budgets by raising tax rates and issuing public debt. The government debt resulting from corruption crowds out both private and public capital and significantly reduces output.

In our paper, we assume a benevolent government, which either adjusts its fiscal instruments to ensure that its budget is balanced ("passive government"), or optimally chooses its instruments to maximise social welfare ("active government"). In the absence of 'grand' corruption, we introduce corruption in its 'petty' form, whereby only a fraction of bureaucrats is corrupt. These public officials by being self-interested, have an informational advantage over the government, a la Acemoglu and Verdier (2000), making it difficult for the latter to monitor them properly. Such informational asymmetry is a realistic feature of many countries, and in particular, among many developing 
countries where corruption is rife. ${ }^{6}$ Within that set-up, corruption features in three distinct ways: On the expenditure side, there are two types of effects: first, corrupt officials inflate the size of the public spending, not for increasing the size of the national cake, but for their own pecuniary gain; secondly, although the amount of public spending is higher than warranted, the productivity arising out of such spending is considerably lower than it would otherwise have been. ${ }^{7}$ On the revenue side, corruption in tax administration implies that not all tax revenues end up in government coffers, as some of it is embezzled by corrupt bureaucrats involved in tax collection. Essentially, a bureaucracy which is more corrupt in every dimension will spend more money given a certain amount of public services, increase productivity by less given a certain amount of public services, and raise less money given a certain tax rate. Although some of these aspects have been captured in previous empirical papers (see Mauro (1995), Tanzi and Davoodi (1997), among others), what has generally been missing is a formalization of all these channels through which corruption affects growth via the government budget constraint. We fill in this gap in the literature by deriving explicit analytical conditions to capture such effects, and supplement these with numerical simulations to assess the magnitude of the different types of corruption.

That corruption may impact independently on both the expenditure and revenue sides of the government's budget can be explained as follows: corruption can distort the composition of expenditures by shifting resources towards items where the possibility of inflating spending and obtaining more "commissions" is higher and also where there is greater scope for indulging in covert corruption, as alluded to by Shleifer and Vishny (1993). Corruption can also alter the manner by which revenues are generated, e.g., by shifting from tax to seigniorage revenues when part of the tax proceeds does not accrue to the government and is usurped, as suggested by Imam and Jacobs (2007), and Tanzi and Davoodi (1997, 2000), who find that corruption reduces total tax revenues by reducing the revenues from almost all taxable sources (including incomes, profits, property, and

\footnotetext{
${ }^{6}$ See Bardhan (1997) and Treisman (2000) on the link between corruption and development.

${ }^{7}$ Olson et al. (2000) attribute the cross-country differences in growth of total factor productivity (TFP) to differences in governance, but do not show any explicit theoretical link between (various forms of) corruption and growth as we do. In Del Monte and Papagni (2001), corruption does lower the quality of public infrastructure supplied to the private sector, but in their paper illegal behaviour manifests through bureaucrats providing the government with low quality goods at the same price as private markets and/or acquiring the same goods at a higher price.
} 
capital gains). The implication is that, ceteris paribus, other means of raising income must be sought, and one of the most tempting of these is seigniorage. Significantly, it has been found that seigniorage is closely linked with inflation (see Cukierman et al. (1992)), and that inflation is positively related to the incidence of corruption (e.g., Al-Marhubi (2000)), while seigniorage, itself, has a negative effect on growth (e.g., Adam and Bevan (2005); Bose et al. (2007)). Such observations provide the motivation for this paper, which explores the influence of various forms of bureaucratic corruption on public spending and finance, and the implications of these for growth and development. ${ }^{8}$

An important element of the model, which generates a link between inflation and growth, is provided by the presence of financial intermediaries who act on behalf of agents. Thus, agents hold money (in addition to capital) in their portfolio, and the portfolio allocation decision is made by those financial intermediaries. Following Diamond and Dybvig (1983) and Espinosa-Vega and Yip (1999, 2002), we consider a scenario in which individuals are subject to random relocation shocks that create a tradeoff between investing in a productive, but illiquid, asset (capital) and a non-productive, but liquid, asset (money). Intermediaries, which receive deposits from individuals, optimize this trade-off by choosing a composition of portfolio that depends on the relative rates of return of the two assets. An increase in inflation, which reduces the return on money, causes a portfolio re-allocation away from capital investment (loans to firms) towards greater cash holdings in order to guarantee adequate provision of liquidity services for those agents who are forced to relocate. As less funds are thereby available to invest in capital, this would be expected to have a depressing effect on growth.

As regards the role of public policy in our paper, an innovation compared to the existing literature is that we consider first the case of a benevolent government which passively adjusts its revenues/expenditures (to ensure a balanced budget) in response to

\footnotetext{
${ }^{8}$ Although income taxation and seigniorage are both considered distortionary as regards growth, there is no consensus on the relative merits of tax versus money financing of public spending. For example, Palivos and Yip (1995) consider income-tax financing to be worse than inflation-tax financing, whereas De Gregorio (1993) generally holds the opposite view. Bose et al. (2007) link the optimal mode of financing to the levels of development, i.e., they find that for low-income (high-income) countries, financing expenditures with revenue generated by income taxation (seigniorage) is less distortionary for growth, and results that are similar in spirit are obtained also by Miller and Russek (1997), and Holman and Neanidis (2006). None of these papers, however, attribute corruption as a factor that affects the relative efficiency of seigniorage as against income taxation.
} 
corruption, and then that of a government which chooses its instruments optimally to maximize a social welfare function comprising of the lifetime utilities of all honest agents over generations. ${ }^{9}$ We show that while the workings of the model are different in the two cases, their predictions are remarkably similar as to the choice of appropriate policy instruments and their respective growth effects, which implies that the issue of whether a government takes a passive or an active stance is actually not that critical. What is more important from a policy implication perspective is for an activist government to be able to get to grips with the quantitative effects of the different forms of corruption, and to thereby direct its energies in attempting to reduce the type of corruption that hurts the economy the most. ${ }^{10}$

In connection with the searching questions raised in the first paragraph, we find that in both the cases referred to above, corruption distorts growth by causing a lower level of government spending and higher rates of income tax and inflation. An interesting result is that, even though in our model corruption is generally harmful to the economy, there is a case where it may be beneficial for economic growth: this is when the government passively adjusts its level of expenditure (without adjusting revenues) in response to corruption; here corruption gives rise to non-monotonic growth effects. Typically, when a government is quite small, higher corruption requires an upward adjustment of the entire budget constraint and, thus, of public expenditure. This, in turn, raises productivity and economic growth. So, clearly, the effect of corruption on growth, and the direction of change in seigniorage and income taxes that is triggered, depends on the types of corruption that exist, and the different channels that are activated as a consequence. Thus, our results could provide a rationale for the empirical findings of papers that report the conditional (or non-monotonic) effects of corruption on growth,

\footnotetext{
${ }^{9}$ Note that corruption at an individual level is undetectable in our model. However, the overall distribution of corruption is known (and is, therefore, exogenously given in the aggregate). Consequently, an optimizing government, designing second-best fiscal policy, takes into account the welfare of all noncorrupt agents.

${ }^{10}$ So, clearly, in both cases there is a link between central government policy and petty corruption, but this link is unidirectional. That is, the causality runs from corruption to fiscal policy (and subsequently growth). The model does not address reverse causality, running from fiscal policy, or any other type of government policy (such as, creation of anti-corruption government agencies), to corruption, because this is beyond the scope of our paper, the objective of which is to isolate the effects of corruption on growth via fiscal policy considerations.
} 
although we associate such non-linearity with the government budget and the government choices.

The rest of the paper is organized as follows. Section 2 presents the analytical model, and characterizes the balanced growth path of the economy. Section 3 analyses the effects of corruption on the key economic variables when a government allows an exogenous adjustment of its fiscal instruments to ensure a balanced budget. Section 4 captures the effects of corruption under an optimizing government. Finally, Section 5 contains a few concluding remarks.

\section{The analytical model}

We consider an overlapping generations economy in which there is an infinite sequence of two-period-lived agents. Each generation of agents is comprised by private citizens (or households) and public officials (or bureaucrats). Households work for firms in the production of output, whilst bureaucrats work for the government in the administration of public policy. All agents work only when young and consume only when old. ${ }^{11}$ Consumption is financed from savings with financial intermediaries that make optimal portfolio choices on behalf of agents by allocating their deposits between liquid and illiquid assets. This role of intermediaries is created by the existence of idiosyncratic relocation shocks which also motivate a demand for liquidity. This financial friction provides a link between the monetary and the real side of the economy.

The government generates revenue by taxing labour income and by printing money (seigniorage), and undertakes expenditures on public goods and services along the lines of Barro (1990), where government spending is productive. Corruption takes shape in three different ways. Firstly, some bureaucrats appropriate tax revenues for themselves; secondly, some bureaucrats inflate the cost of public services; and thirdly, corruption reduces the efficiency of the public good in the production process. ${ }^{12}$ Finally,

\footnotetext{
${ }^{11}$ This assumption is found also in Espinosa-Vega and Yip (1999, 2002), Bose et al. (2007), Blackburn et al. (2010), and Litina and Palivos (2016), among others.

${ }^{12}$ In our model, only (a fraction of) bureaucrats are corrupt. There is no tax evasion on the part of households, who are all honest and tax-compliant. This feature is different from Holman and Neanidis (2006), Ivanyna et al. (2016) and Litina and Palivos (2016), for instance, where a fraction of private household income is not reported for tax purposes.
} 
firms, of which there is a unit mass, conduct all of their business in perfectly competitive product and factor markets. The economy is described in more detail as follows.

\subsection{Agents}

There is a constant population (normalised to one) of two-period-lived agents belonging to overlapping generations of dynastic families. Agents are divided at birth into a fraction, $\mu$, of households and a remaining fraction, 1- $\mu$, of bureaucrats. ${ }^{13}$ Both households and bureaucrats work only when young and consume only when old, deriving lifetime utility according to

$$
U_{t}=-\frac{c_{t+1}^{-\sigma}}{\sigma}, \sigma>0
$$

where $c_{t+1}$ denotes old-age consumption.

All young agents are endowed with the same unit amount of labour which is supplied inelastically to a given occupation (private employment or public service) in return for the same labour income of $w_{t} \cdot{ }^{14}$ This income is deposited as savings with financial intermediaries. As in Espinosa-Vega and Yip (1999, 2002), we introduce some uncertainty into the model by assuming that a typical agent is born at a point in time in one particular location, where he resides in the first period of his life. In the second period, with probability $q(0<q<1)$, this agent relocates to another location. The uncertainty of individuals about their future location is important for determining the composition of savings which can take two forms - a liquid, but unproductive, asset (money) and an illiquid, but productive, asset (capital). Although the return on capital is higher than that of money, there nevertheless exists some demand for cash as the latter is 'mobile' because of its liquidity and is therefore demanded by agents who relocate. We

\footnotetext{
${ }^{13}$ As in Blackburn et al. (2006) and Sarte (2000), we abstract from issues relating to occupational choice and assume that agents are differentiated at birth according to their abilities and skills. This, in turn, means that households cannot choose to become bureaucrats, or vice-versa, even if they wish to take advantage of the illegal income opportunities available to the latter group of agents.

${ }^{14}$ This has a similar interpretation to the allocation of talent condition as in Acemoglu and Verdier (2000), whereby the government is able to induce potential bureaucrats to take up public office by paying them salaries that they would earn elsewhere. Note that one does not need to invoke labour mobility across sectors to ensure this. Instead, the mechanism is that if an official accepts a salary less than $w_{t}$, he is immediately identified as being corrupt and dismissed without pay, as in Blackburn et al. (2006), which means that all bureaucrats would refrain from accepting a wage other than $w_{t}$.
} 
assume that these shocks are identically and independently distributed across agents who prefer to save through intermediaries, rather than by themselves, because doing so allows them to exploit the law of large numbers in eliminating individual risk. We study this in detail in our subsequent analysis.

\subsection{Firms}

Households work for firms in the production of output. There is a unit mass of firms, each of which combines $l_{t}$ units of labour with $k_{t}$ units of capital to produce $y_{t}$ units of output according to

$$
y_{t}=A l_{t}^{\alpha} k_{t}^{\beta}\left[\xi(1-\chi \lambda) G_{t}\right]^{1-\beta}
$$

$(A>0, \alpha, \beta \in(0,1))$, where $G_{t}$ denotes productive public goods and services.

We assume that expenditure on public goods and services is a fixed proportion of output, $G_{t}=\theta y_{t},(\theta \in(0,1))$. The actual productivity of public goods and services, however, is less than what would have been in the absence of corruption. Specifically, as it is made clear in the next section, $\xi(1-\chi \lambda)$ is the "effective" productivity of public spending, with $\chi \lambda$ being the amount by which corruption reduces efficiency. This consideration is consistent with Bandeira et al. (2001) and Mauro (2004), where corruption reduces the productivity of effective public investment. ${ }^{15}$

Given this, the firm maximises its profits by hiring labour at the real wage rate $w_{t}$ and renting capital at the real interest rate $r_{t}$ so as to satisfy the condition of perfect competition in factor markets. Observe that equilibrium in the labour market requires $l_{t}=\mu$, so that with the use of $G_{t}=\theta y_{t}$, equation (2) can be written as:

$$
y_{t}=b k_{t}
$$

\footnotetext{
${ }^{15}$ Corruption has also been found to diminish the productivity of private capital and total factor productivity. The former effect is illustrated by Lambsdorff (2003) while the latter by Dar and AmirKhalkhali (2002).
} 
where $b \equiv\left(A \mu^{\alpha}[\xi(1-\chi \lambda) \theta]^{1-\beta}\right)^{\frac{1}{\beta}}>0$ so that output effectively reduces to an $A k$-type technology. ${ }^{16}$

Using (2'), the equilibrium factor prices are shown to be

$$
\begin{aligned}
& w_{t}=\frac{\alpha b}{\mu} k_{t}, \\
& r_{t}=r=\beta b,
\end{aligned}
$$

with equilibrium wages being proportional to the capital stock and the equilibrium interest rate being constant.

\subsection{Bureaucrats}

Bureaucrats work for the government in the administration of public policy. Specifically, public officials are divided into those that work on revenue collection $(v)$ and those that act in the procurement of the public good (1-v). This means that $v(1-\mu)$ bureaucrats collect revenues and $(1-v)(1-\mu)$ procure public goods. The revenues collected by the bureaucrats are represented by a fixed proportional tax rate, $\tau \in(0,1)$, the government levies on wage earnings, $w_{t}$. The public goods and services procured by the bureaucrats have a real value $G_{t}$ and, as described above, contribute to the efficiency of the firm's output production. From the $v(1-\mu)$ bureaucrats that collect revenues, we assume that (1$\eta)$ are corrupt. We also assume that a fraction $\chi$ of the officials that procure the public good are also corrupt. ${ }^{17}$

The above imply that on the revenue side, collected tax revenues by each bureaucrat correspond to $\tau w_{t} / \nu(1-\mu)$. However, only the non-corrupt among the bureaucrats involved in revenue collection bring the tax proceeds to the government.

\footnotetext{
${ }^{16}$ In our case, the use of an $A k$-type technology can be justified by a number of reasons. First, it is possible to justify the absence of diminishing returns by considering a broad concept of capital. Second, research (e.g., Turnovsky, 2004) suggests that the growth effects of fiscal policy may be long-lasting, a feature consistent with the $A k$ model. Finally, it is often argued (e.g., in Barro and Sala-i-Martin, 1995) that in the presence of slow cross-country convergence, the growth effects in an $A k$ model provide a satisfactory approximation to the average growth effects over a long period in the neoclassical model.

${ }_{17}$ The distinction between corruptible and non-corruptible bureaucrats may reflect differences in proficiencies at being corrupt or differences in moral attitudes towards being corrupt (e.g., Acemoglu and Verdier (2000) and Blackburn et al. (2006)). At a secondary level, we also make a distinction as to the number of corrupt officials on the two sides of the government budget constraint: $(1-\eta) v \neq \chi(1-v)$.
} 
Hence, total tax revenues provided to the government by all non-corrupt officials are described by $\eta \mathcal{i} w_{t}$. As a result, tax revenues appropriated by corrupt officials are given by $(1-\eta) \tau w_{t}$. On the spending side, each official is responsible for the procurement of $\theta_{y_{t}} /(1-v)(1-\mu)$ public goods, which corresponds to the amount each non-corrupt official procures. Each corrupt official, on the other hand, artificially inflates public spending to an amount equal to $\theta(1+\varepsilon) y_{t} /(1-\nu)(1-\mu), \varepsilon>0$. Here, $\varepsilon$ represents the size by which spending is inflated due to corruption. Therefore, effective or total spending on public goods $\left(g_{t}\right)$ is given by public spending by non-corrupt bureaucrats plus that by corrupt bureaucrats, representing the first and second terms (after the first equality) respectively, of the expression below:

$$
g_{t}=(1-\chi) \theta y_{t}+\chi(1+\varepsilon) \theta y_{t}=(1+\chi \varepsilon) \theta y_{t} .
$$

This means that actual spending on public goods increases due to corrupt practices as only $\theta y_{t}$ of total public spending is utilised in the firms' production function. The remaining amount of $\chi \varepsilon \theta y_{t}$ represents the illegal income (i.e., embezzlement) of corrupt bureaucrats. Such practices have been stressed empirically by Tanzi and Davoodi (1997) who show that corruption inflates public capital expenditure, as the scope for indulging in corrupt practices is much higher for this type of spending.

As mentioned in the previous section, corruption in our model also leads to a productivity loss, but only in the context of the procurement of public goods by corrupt bureaucrats. Specifically, we assume that each unit of the public good yields a productivity of $\xi$ units when procured by $(1-\chi)$ non-corrupt bureaucrats, but only $\xi(1-\lambda)$ units when this is procured by the $\chi$ corrupt bureaucrats. Therefore, the parameter $\lambda \in(0,1)$ captures the productivity loss of public spending due to corrupt practices. ${ }^{18}$ Incorporating this aspect, we find that total productivity generated from public goods is

\footnotetext{
${ }^{18}$ Some of the typical channels through which corruption affects the productivity of capital are as follows: the lure of possible higher returns to rent-seeking activities could crowd out productive investment, as in Murphy et al. (1993). Romer (1994) contends that corruption, acting as a tax on profits, could thwart the adoption of new technology, particularly if an initial lump-sum payment has to be incurred. Also, there is considerable uncertainty concerning the enforceability of corruption contracts: enforcement costs are likely to be larger than regular contracts, and moral hazard is an issue, as pointed out by Boycko et al. (1995). This uncertainty is likely to result in lower investment and growth.
} 
given by $\xi(1-\chi \lambda)$, as noted in the previous section. It is clear, therefore, that a higher value of $\lambda$, which represents more corruption, leads to lower productivity of public spending. ${ }^{19}$

The importance of (a high level of) productivity with which physical and human capital are used in contributing to output per worker has been stressed by Hall and Jones (1999). They contend that social infrastructure - which comprises of the institutions and government policies that make up the economic environment within which economic agents operate - contributes to the success on each of these fronts. They mention thievery, expropriation and corruption among the sources of "diversion" of social infrastructure. Recently, Faruq et al. (2013) have provided estimates of the negative effect of corruption on firm productivity in Ghana, Kenya, and Tanzania: a one-standarddeviation increase in corruption reduces firm efficiency between 15\%-20\%, depending on whether the firm is input- or output-oriented. Likewise, in our set-up, government procurement of public goods could be interpreted as contributing to social infrastructure and firm productivity, with both being undermined in the presence of corruption. ${ }^{20}$

\subsection{Government}

A benevolent government provides public services, $g_{t}$, that (partially) contribute to private productivity, as in Barro (1990), Chen (2006), Ghosh and Gregoriou (2008), etc. The government also pays bureaucrats' salaries, which, as already described, earn the same salaries as that of households, $w_{t}$. It follows then that the total real wage bill for the government is $(1-\mu) w_{t}$. The revenue side of the government's budget constraint comprises seigniorage and tax receipts. The first term on the left-hand-side of equation (6) denotes real revenue from money printing or seigniorage (as in Myles and Yousefi, 2015), while the second term gives the actual amount of tax revenue available to the government:

\footnotetext{
${ }^{19}$ One could consider the case where the corrupt procurers of public goods that inflate spending are different from the ones responsible for the productivity loss from public goods. This would, however, introduce some complexity into the model without delivering additional insights, which is why we have assumed there is one set of bureaucrats involved in the expenditure side of the government budget constraint.

${ }^{20}$ In its various forms, corruption has been modelled as a phenomenon that occurs with certainty. One should not discount however that a part of corruption's burden stems from its random nature--see Wei (1997).
} 


$$
\frac{M_{t}-M_{t-1}}{P_{t}}+\eta \tau w_{t}=g_{t}+(1-\mu) w_{t},
$$

where from (5) we need to assume that $(1+\chi \varepsilon) \theta<1$ so as to place an upper limit to government spending as a fraction of output.

In the analysis, we consider two different ways the government responds to corruption. First, we assume that the government allows for an exogenous adjustment of its fiscal instruments in order to ensure a balanced budget. We then consider the case where the government optimally chooses its instruments to maximize some social welfare function. The comparison between exogenous and endogenous fiscal policy adjustment gives us the opportunity to examine the extent by which the link between corruption and growth varies according to policy-making decisions.

\subsection{Financial intermediaries}

Financial intermediaries manage the savings of individuals and make portfolio allocation decisions in the interest of their depositors. The portfolio consists of money and capital, each of which has benefits and costs: money provides liquidity insurance for agents who are relocated, but does not pay any rate of interest; capital provides a rate of return for agents who do not relocate, but is unavailable to those who move. Individuals take the help of financial intermediaries - who are viewed as being formed as cooperatives from young households, as in Diamond and Dybvig (1983) - as the latter are able to exploit the law of large numbers and thereby to eliminate individual risk. ${ }^{21}$ Let $\delta(0<\delta<1)$ be the fraction of deposits lent to firms (i.e. held in the form of capital), which implies that a (1$\delta$ ) fraction is held in the form of money. Also, let $i_{t}\left(I_{t}\right)$ denote the gross real rate of return paid to depositors who move (do not move) location. Finally, the variable, $R_{t}\left(\equiv P_{t} / P_{t+1}\right)$, which is the gross rate of deflation, denotes the real rate of return on money holdings, and is taken as given by the financial intermediaries.

\footnotetext{
${ }^{21}$ Instead of assuming that financial intermediaries operate as cooperatives drawn from households, one could consider such intermediaries as competing for the depositors, as in Bencivenga and Smith (1993). In that case, any (extra) economic profits that may accrue would be offered to depositors and therefore be competed away among the intermediaries, which in effect implies that competition leads to financial intermediaries acting in the best interests of depositors.
} 
It ought to be noted that for households, as well as for non-corrupt bureaucrats, labour income $\left(w_{t}\right)$ is the only source of earnings. However, for corrupt public officials involved in revenue collection, $(1-\eta) \tau w_{t}$ is the amount appropriated illegally, while for the corrupt bureaucrats involved in public procurement, $\chi \varepsilon \theta y_{t}$ represents the amount embezzled. We assume that these corrupt officials manage to escape punishment either because their actions are undetectable and/or governments find it difficult to implement punishment strategies due to resource constraints (which is true especially in developing countries). We also assume that whatever is embezzled by such officials is saved via "non-standard" channels: in other words, the usual mode of saving via financial intermediaries described above only applies to the legal component of the income of corrupt officials (i.e., labour income), but not to the funds embezzled while undertaking revenue collection and public procurement. If that would have been the case, then the offenders would be exposed with certainty. ${ }^{22}$

The optimisation problem facing financial intermediaries involves choosing $\delta_{t}, i_{t}$ and $I_{t}$, so as to maximise the expected utility of a representative depositor

$$
V_{t}=-q \frac{\left[(1-\tau) w_{t} i_{t}\right]^{-\sigma}}{\sigma}-(1-q) \frac{\left[(1-\tau) w_{t} I_{t}\right]^{-\sigma}}{\sigma},
$$

subject to

$$
\begin{gathered}
q i_{t}=\left(1-\delta_{t}\right) R_{t}, \\
(1-q) I_{t}=\delta_{t} r .
\end{gathered}
$$

The financial intermediaries' portfolio problem is to maximise the expected welfare of a depositor who deposits his entire labour income with them; and this depositor faces a probability, $q$, of being relocated (thereby receiving $i_{t}$ ), and a probability, 1-q, of remaining in the same location (thereby receiving $I_{t}$ ). This is given by equation (7) above. The resource constraint in (8) conveys the information that the financial intermediaries are able to meet the liquidity needs of the depositors who do

\footnotetext{
${ }^{22}$ This means that illegal income can be saved via "non-standard" channels, such as by being placed under the mattress, or being forwarded to an underground economy. In an open economy environment, they could also be transferred to foreign financial entities. As indicated, however, we abstract from these considerations because we can examine the effects of corruption without having to make any assumptions about the uses of these illegal funds.
} 
relocate using their real money holdings, while (9) shows that the intermediaries are able to make the requisite payment (out of their lending to producers of capital) to the fraction of depositors who do not relocate.

In equilibrium, it is necessary that cash is dominated by capital in terms of rate of return, that is, $r_{t}>R_{t}$. Otherwise, lending to firms is not the preferred option. At the same time, this condition requires financial intermediaries to hold currency for the sole reason of meeting the liquidity needs of relocated agents.

The solution of this problem yields the optimal share of deposits invested in capital to be

$$
\delta_{t}=\frac{\left(\frac{q}{1-q}\right)\left(\frac{R_{t}}{r}\right)^{\frac{\sigma}{1+\sigma}}}{1+\left(\frac{q}{1-q}\right)\left(\frac{R_{t}}{r}\right)^{\frac{\sigma}{1+\sigma}}} \equiv \Delta\left(R_{t}, r\right),
$$

where $\Delta_{R}>0$, implying that a decrease in $R_{t}$, the return on money, induces intermediaries to allocate a larger fraction of deposits towards cash holdings. This is because in the presence of higher inflation (i.e., lower $R_{t}$ ), intermediaries find it difficult to provide sufficient liquidity for agents who relocate, unless they hold more money. This income effect of a change in inflation implies that more money needs to be held and a smaller proportion of deposits can be allocated to productive capital. ${ }^{23}$

\subsection{Balanced growth equilibrium}

Along the balanced growth equilibrium, which is unique and stable, all variables grow at the same rate. The growth rate is determined from the capital market equilibrium condition where the total demand for capital by firms, $k_{t+1}$, equals the total supply of capital by financial intermediaries, $w_{t} \delta_{t}$ (which equals the investment in capital made by the intermediaries out of the deposits accruing from all agents).

\footnotetext{
${ }^{23}$ This result is by now standard in studies that use this modeling framework. See Espinosa-Vega and Yip (1999, 2002).
} 
From $k_{t+1}=(1-\tau) w_{t} \delta_{t}$, we use equation (3) to obtain $k_{t+1} / k_{t}=(1-\tau) \alpha b \delta_{t} / \mu$, or

$$
\gamma \equiv \frac{k_{t+1}}{k_{t}}=\frac{(1-\tau) \alpha b}{\mu} \Delta(R, r),
$$

where $\gamma$ is the economy's equilibrium growth rate. From eq. (11), it is clear that $\gamma$ responds positively to $R_{t}$. This is because a higher return on money (captured by higher $R_{t}$ ) eases the liquidity constraint for financial intermediaries, thereby enabling agents' savings to be channelled towards capital, which spurs growth.

Denoting $m_{t} \equiv M_{t} / P_{t}$ as the real value of money balances, we can express the money market clearing condition as $m_{t}=(1-\tau) w_{t}\left(1-\delta_{t}\right)$, or using (3) and (10) obtain

$$
m_{t}=\frac{(1-\tau) \alpha b}{\mu}[1-\Delta(R, r)] k_{t}
$$

An increase in $R_{t}$ (lower inflation) implies that lower money holdings are required to satisfy the liquidity demands of households who relocate, and this is reflected in eq. (12).

Of course, in the steady-state, we have $\gamma \equiv k_{t+1} / k_{t}=m_{t+1} / m_{t}=y_{t+1} / y_{t}$. Using $m_{t}=\gamma m_{t-1}$, the government revenue from seigniorage can be expressed as $\left(M_{t}-M_{t-1}\right) / P_{t}=(\gamma-R) m_{t} / \gamma$. Then, combining equations (12) and (11) we obtain $\left(M_{t}-M_{t-1}\right) / P_{t}=(\gamma-R) k_{t}[1-\Delta(R, r)] / \Delta(R, r)$.

Next, using the above expression for seigniorage, along with equations (2'), (5), and (3), we can rewrite the government budget constraint equation, (6), as

$$
\left(\frac{\gamma-R}{b}\right)\left[\frac{1-\Delta(R, r)}{\Delta(R, r)}\right]+\eta \frac{\alpha}{\mu} \tau=(1+\chi \varepsilon) \theta+\frac{(1-\mu) \alpha}{\mu} .
$$

The first term on the left-hand-side of the above expression denotes the seigniorage revenue of the government. This seigniorage revenue is the product of the (productivityadjusted) inflation tax rate and the inflation tax base. The second term to the left of the equality is the tax revenue accruing to the government from the $\eta$-proportion of noncorrupt tax collectors. The first term to the right of the equality is the spending on procurement of public goods (which includes the inflating of public expenditures by 
corrupt bureaucrats), while the second term on the right-hand-side represents the salary payments made to bureaucrats, who comprise $(1-\mu)$-proportion of the population.

As our task is to understand the effects of corruption (in its different forms) on economic growth, and given that growth and fiscal instruments are jointly determined through the government budget constraint, we need to consider the simultaneous system described by equations (11) and (13). Accordingly, we need to take the total derivatives of equations (11) and (13). Doing so, yields

$$
\begin{aligned}
d \gamma-\frac{(1-\tau) \alpha b}{\mu} & \frac{\partial \Delta}{\partial R} d R+\frac{\alpha b}{\mu} \Delta d \tau-\left[\Delta+b \frac{\partial \Delta}{\partial r} \frac{\partial r}{\partial b}\right] \frac{(1-\tau) \alpha}{\mu} \frac{\partial b}{\partial \theta} d \theta= \\
= & {\left[\Delta+b \frac{\partial \Delta}{\partial r} \frac{\partial r}{\partial b}\right] \frac{(1-\tau) \alpha}{\mu} \frac{\partial b}{\partial \chi} d \chi+\left[\Delta+b \frac{\partial \Delta}{\partial r} \frac{\partial r}{\partial b}\right] \frac{(1-\tau) \alpha}{\mu} \frac{\partial b}{\partial \lambda} d \lambda } \\
\frac{1}{b} \frac{1-\Delta}{\Delta} d \gamma- & {\left[\frac{1-\Delta}{\Delta}+(\gamma-R) \frac{1}{\Delta^{2}} \frac{\partial \Delta}{\partial R}\right] \frac{1}{b} d R+\frac{\eta \alpha}{\mu} d \tau-} \\
- & \left\{1+\chi \varepsilon+\left[(1-\Delta) \frac{1}{b}+\frac{1}{\Delta} \frac{\partial \Delta}{\partial r} \frac{\partial r}{\partial b}\right](\gamma-R) \frac{1}{b} \frac{1}{\Delta} \frac{\partial b}{\partial \theta}\right\} d \theta= \\
= & -\frac{\alpha}{\mu} \tau d \eta+\left\{\theta \varepsilon+\left[(1-\Delta) \frac{1}{b}+\frac{1}{\Delta} \frac{\partial \Delta}{\partial r} \frac{\partial r}{\partial b}\right](\gamma-R) \frac{1}{b} \frac{1}{\Delta} \frac{\partial b}{\partial \chi}\right\} d \chi+ \\
& +\left[(1-\Delta) \frac{1}{b}+\frac{1}{\Delta} \frac{\partial \Delta}{\partial r} \frac{\partial r}{\partial b}\right](\gamma-R) \frac{1}{b} \frac{1}{\Delta} \frac{\partial b}{\partial \lambda} d \lambda .
\end{aligned}
$$

We now use equations (11') and (13') to perform a number of comparative statics exercises, highlighting the role of the different aspects of corruption on the revenue and expenditure sides of the government's budget, and eventually on growth. As already mentioned, the analysis distinguishes between the exogenous adjustment and the optimal choice of instruments by the government. These are described in the following sections, and enable us to obtain some interesting results.

\section{Corruption and growth in the decentralized equilibrium}

In this section, we examine the impact of the various forms of corruption (collection of tax revenue, procurement of public goods, and productivity of public goods) on growth by considering a passive stance by the government. That is, in response to corruption, the government is assumed to adjust its fiscal instruments to keep a balanced budget. To this

effect, we examine independently the revenue generating and spending instruments. With 
regard to the creation of public revenue, we examine three distinct cases: (i) only seigniorage can vary, (ii) only the income tax rate can vary, (iii) both revenue sources are allowed to vary. We finally consider the case where the government keeps its sources of revenue constant and allows only exogenous adjustments in public spending.

\subsection{Seigniorage as the single source of variation in government revenue}

Even though this may reflect an extreme case, the reliance of many countries (developing countries in particular) on seigniorage is a reality, often due to an inefficient tax system, making seigniorage a relatively inexpensive source of revenue (see Cukierman et al. (1992), De Gregorio (1993), Roubini and Sala-i-Martin (1995)). In our model, this case amounts to setting changes in the rate of income tax equal to zero, $d \tau=0$, in equation (13'). This, in turn, implies that changes in seigniorage are used to match any changes in public spending (level effect), or compensate for any changes in tax revenue for a given level of government outlays (revenue composition effect).

Appendix A(I) illustrates how equations (11') and (13') look in matrix form under the above condition. It also shows how the gross rate of deflation (or inflation), $R$, and the rate of economic growth, $\gamma$, react to higher incidents of corruption as these materialise through the three different channels we consider. The results of these exercises take shape through the propositions below.

Proposition 1: Given a path of public expenditure $(d \theta=0)$ and no fiscal consolidation $(d \tau=0)$, an increase in corruption related with the $(i)$ collection of tax revenue, (ii) procurement of public goods, or (iii) productivity of public goods, increases the rate of inflation and decreases the steady-state growth rate.

Part (i) of the proposition reflects a negative effect of corruption on growth through changes in the composition of public revenue toward more seigniorage. This finding is consistent with the empirical evidence provided by Blackburn et al. (2010) and the work of De Gregorio (1993). The former shows that a shift in the composition of public revenue toward more seigniorage at the expense of lower income taxes yields negative growth effects, while the latter highlights the role of an inefficient tax system 
which due to high tax collection costs produces high inflation rates and low economic growth. The incidence of tax collection costs across countries has been documented by Bird and Zolt (2005), who report that developed countries devote roughly one percent of tax revenues to cover the budgetary costs of tax collection. The costs of tax administration for developing countries, on the other hand, are substantially higheralmost three percent of tax revenues, according to Gallagher (2005). In our setup, the source of this inefficiency in tax administration arises out of corruption in the collection of public revenue.

Part (ii) of Proposition 1 corresponds to a negative effect of corruption on growth through changes in the level of public revenue toward more seigniorage - for a given amount of revenue collected through taxation - due to an increase in effective public spending. At the same time, corruption diminishes the productivity of public spending which has a direct negative effect on growth. This result is in line with the empirical evidence provided by Adam and Bevan (2005) and Bose et al. (2007), who illustrate that greater reliance on seigniorage as a means of financing public expenditure generates distortionary effects on growth.

This case represents an example of a situation where a particular type of corruption that operates on the expenditure side of the government budget constraint (manifested through a higher value of $\chi$ ), affects the growth rate not only via inflated public spending, but also via shifts in revenues toward more seigniorage. Even though in both parts (i) and (ii) the outcome of higher corruption is lower economic growth, the difference is that in the former case the negative growth effect of a rise in seigniorage is a direct consequence of the fact that less tax revenues are generated (lower $\eta$ ). In the latter case, however, the growth effect (via higher $\chi$ ) of higher seigniorage is indirect strengthening the direct negative productivity effect on growth.

In addition, both (i) and (ii) imply that higher corruption induces higher inflation as the government relies more on seigniorage, a result empirically confirmed by AlMarhubi (2000). Our contribution, therefore, lies in the fact that we identify two distinct channels via which corruption could lead to higher inflation: lower $\eta$ (revenue side of the budget) or higher $\chi$ (expenditure side of the budget). 
Part (iii) of Proposition 1 reflects the direct negative effect of corruption on growth via a decline in the productivity of public goods, and an indirect negative effect through changes in the composition of public revenue toward more seigniorage causing inflation to rise (decline in $R$ ) and the growth rate to fall. As regards the direct productivity effect, Salinas-Jimenez and Salinas-Jimenez (2007), by considering a sample of 22 OECD countries for the period 1980-2000, they show that corruption affects TFP growth, with economies that have lower levels of corruption recording, on average, faster growth rates. A similar result is obtained by Faruq et al. (2013) with regard to the adverse effect of corruption on the firm productivity of 900 African firms, and O'Toole and Tarp (2014) who identify a strong negative effect of corruption on capital investment efficiency amongst small- and medium-sized enterprises in 90 developing and transition economies.

Here, too, the change in an expenditure-side parameter has an indirect effect on growth via the revenue side of the government budget constraint. Note that the link between higher corruption, higher inflation and lower growth remains as before; here, due to lower effective public spending (due to higher $\lambda$ ) being financed by seigniorage.

To offer some examples, and further confirm the findings outlined in Proposition 1 , we conduct a series of numerical simulations. The goal is to illustrate the effects of corruption on the fiscal instruments and economic growth by setting plausible parameter values for the exogenous variables so as to generate realistic income tax and growth rates. Table 1 presents the benchmark values of the exogenous variables that determine the size of the endogenous variables. The values of the exogenous parameters are in line with the cited studies in the last column, while the corruption parameters reflect plausible values. As it concerns the endogenous variables, in the benchmark framework financial intermediaries hold only $14.5 \%$ of their deposits in the form of capital despite the much higher rate of return on this asset (26.5\%) compared to money (3\%). This result is sensible, however, given the relatively high relocation probability agents are facing (55\%). The government uses $20 \%$ of national income toward public spending, while the income tax rate is determined at $26.8 \%$. Finally, the economy grows at a rate of $4.26 \%$.

Panel A of Table 2 shows how the endogenous variables of interest vary in response to changes in the corruption parameters when the inflation rate is the only fiscal 
instrument that is allowed to change. The main message, in line with Proposition 1, is that the inflation rate rises (lower $R$ ) and the equilibrium growth rate declines due to higher occurrence of corruption of any type (lower $\eta$, or higher $\chi$ or $\lambda$ ). So, in response to higher corruption, there needs to be a rise in seigniorage revenue via the inflation tax (in the absence of the income tax instrument) in order to satisfy the government budget constraint. The size of the change in the endogenous variables, however, varies across the types of corruption with both inflation and growth being most sensitive to corruption associated with the collection of public revenue, $\eta$.

\subsection{Income tax as the single source of variation in government revenue}

Although this too, is an extreme case, it is the limiting case of maintaining a very low rate of inflation. This is the experience of many developed countries, like the US and UK, and members of the European Union which have quite independent central banks with a commitment to maintain inflation within a specified target--as we know there is a strong positive relation between inflation and seigniorage (see Cukierman et al. (1992)). Very low reliance on the inflation-tax as a source of revenue could be expected from governments abandoning a regime of financial repression of the sort described by Roubini and Sala-i-Martin (1995). ${ }^{24}$

Within our model, this case corresponds to setting changes in the rate of inflation equal to zero in equation (13'). This, in turn, implies that any changes in spending are matched by changes in the tax rate. Using this condition, the new matrix form expression for the set of equations (11') and (13') appears in Appendix A(II). This Appendix also presents the comparative static exercises as to the effect of the three types of corruption on the income tax and growth rates. Once again, we present the findings of these experiments in the form of the following Proposition.

Proposition 2: Given a path of public expenditure $(d \theta=0)$ and a constant inflation rate $(d R=0)$, an increase in corruption related with the (i) collection of tax revenue, (ii)

\footnotetext{
${ }^{24}$ From a policy perspective, the World Bank (1989) has stressed the importance of reducing permanently the need for seigniorage revenues.
} 
procurement of public goods, or (iii) productivity of public goods, increases the income tax rate and decreases the steady-state growth rate.

Part (i) is a straightforward result stating that if corruption causes income tax revenue to drop, in the absence of an alternative method of raising revenue, the government has no other option but to increase the income tax rate in order to generate revenue to match the revenue lost due to corruption. ${ }^{25}$ As a result, the increase in the rate of income tax leads to a lower growth rate by diminishing the after tax income available for investment purposes.

Part (ii) reflects an effect of corruption on growth through changes in both the level and the productivity of public spending. Intuitively, an increase in $\chi$ raises the size of government spending. At the same time, however, it decreases the productivity of output, $b$, and therefore the income tax base, which would have caused seigniorage revenue to rise (via a shift from income taxation). But given the constant inflation rate, the income tax rate has to rise in equilibrium to maintain the government budget constraint. Then, together with the fall in $b$, the growth rate falls.

As for part (iii) of Proposition 2, re-writing equation (13) as

$$
(\gamma-R)\left[\frac{1-\Delta(R, r)}{\Delta(R, r)}\right]+\frac{\eta \alpha b}{\mu} \tau=(1+\chi \varepsilon) \theta b+\frac{(1-\mu) \alpha b}{\mu}
$$

shows that an increase in corruption associated with a lower output productivity of public goods, $b$, causes both the revenue and expenditure elements of the government budget to decline. It is unclear, however, which element of the budget will decrease by a greater extent. If the decline in expenditure falls below (exceeds) the drop in revenue, then given a fixed inflation rate, this will induce a higher (lower) income tax rate to ensure a balanced budget. Our calculations show that the tax rate is actually higher as a result of the rise in $\lambda$, which implies, therefore, that the decline in spending is lower than the reduction in revenue. This finding, then, is consistent with a direct negative effect of

\footnotetext{
${ }^{25}$ De Gregorio (1993), in a model without corruption, shows that if the government is able to collect a smaller fraction of tax revenues (reflecting a more inefficient tax system), the tax rate has to increase when the rate of money creation is zero.
} 
corruption on growth through a decline in the productivity $(b)$ of the public good, and a complementary negative effect via a higher income tax rate $(\tau)$.

We assess numerically the findings of Proposition 2 by changing the values of the corruption parameters one at a time and by allowing only the income tax rate to vary. The results appear in Panel B of Table 2, where a higher tax rate and a lower growth rate result in response to higher corruption. So, in response to higher corruption, there needs to be a rise in tax revenue via the income tax instrument (in the absence of seigniorage revenue) in order to satisfy the government budget constraint. This is true for any form of corruption, although the impact is, as in Proposition 1, greater in magnitude for corrupt tax collectors (lower $\eta$ ). Overall, the estimates in Panel B confirm Proposition 2.

In sum, by putting together the findings of Proposition 1 and 2, the implication is that both of the government revenue-creation instruments have to rise due to corruption and that their subsequent effects on growth are negative, regardless of the type of corruption taking place. This is also the implication drawn from the numerical simulations in Panels A and B of Table 2. Thus, our framework suggests that corruption (of every type) influences a government's revenue instruments in the same direction while, at the same time, diminishes economic growth.

\subsection{Adjustments in public expenditure}

We now examine the case where the government keeps its sources of revenue constant (both the tax rate and rate of inflation) and allows only exogenous adjustments in spending. Thus, the effects of corruption are now transmitted through the expenditure side of the government budget constraint. Appendix A(III) illustrates how equations $\left(11^{\prime}\right)$ and (13') look in matrix form under such a restriction. The impact of the different forms of corruption on the share of government expenditure (as fraction of GDP) and on economic growth, is summarized in the following proposition.

Proposition 3: Given a constant income tax rate $(d \tau=0)$ and a constant inflation rate $(d R=0)$, an increase in corruption related with the (i) collection of tax revenue, (ii) procurement of public goods, or (iii) productivity of public goods, has an ambiguous effect on both the share of government expenditure and the steady-state growth rate. 
The intuition of these outcomes is best illustrated with the use of equation (14), and resembles the explanations given for Proposition 2(ii). Specifically, a decrease in $\eta$ decreases the revenue side in equation (14). The question now is: in which direction shall $\theta$ move to equilibrate the budget? Keeping in mind that output productivity, $b$, is positively influenced by changes in $\theta$, we have a number of plausible outcomes. On the one hand, $\theta$ can increase, so that along with the increase in $b$, the expenditure side in equation (14) rises. But the rise in $b$ will also increase the revenue side, so that if the rise in $b$ exceeds the decline in $\eta$, a balanced budget is possible. Alternatively, $\theta$ can decline in response to a drop in $\eta$ so that both sides of the budget will go down until a new equilibrium is achieved, assuming that the spending side will decrease by more. Moreover, the change in $\theta$ causes a change in the growth rate of output in the same direction through its impact on productivity. Thus, it is unclear in which way $\theta$ will adjust due to higher corruption on the collection of taxes, leading to ambiguous growth effects.

An increase in corruption related with the procurement of public goods, $\chi$, leads to a decline in $b$ so that the revenue side of equation (14) declines, while total expenditure may either fall or rise. If expenditures rise, then for a balanced budget, $\theta$ needs to drop, which will further reduce $b$. The double drop in $b$, due to the original increase in $\chi$ and the subsequent decreases in $\theta$, diminishes the rate of growth. If, on the other hand, spending goes down by more than revenue, then for a balanced budget, $\theta$ will rise. This, in turn, will drive up both sides of the constraint. In this case, the offsetting effect of a higher $\chi$ and higher $\theta$ on productivity will have an ambiguous effect on growth. As before, this type of corruption also has unclear implications for the share of government spending and output growth.

Finally, an increase in $\lambda$, by decreasing output productivity, causes both sides of the budget to decline. But it is not identifiable which of the sides will decrease by more. If spending declines by more (less), then $\theta$ needs to rise (decline) to rebalance the budget. Once again, therefore, the impact of corruption is generally ambiguous. However, the general ambiguity of the effect of all types of corruption on both government spending and long-run growth can be identified as being related to a single variable: the size of 
public expenditure relative to the size of the economy, $g / y$. The following corollary illustrates this.

Corollary 3.1: Given a constant income tax rate $(d \tau=0)$ and a constant inflation rate $(d R=0)$, if the share of government expenditure as a fraction of total economic activity is relatively large (small), an increase in corruption related with the (i) collection of tax revenue, (ii) procurement of public goods, or (iii) productivity of public goods, decreases (raises) both the share of public expenditure and the steady-state growth rate.

The exact expression of the threshold value of government spending-to-output appears at the end of Appendix $\mathbf{A}(\mathbf{I I I})$. If $g / y$ is relatively large, a decrease in $\eta$ which decreases the revenue side in equation (14), calls for a decline in $\theta$ so that both sides of the constraint decrease. Given that $g / y$ is large, the expenditure side will decrease by a greater amount to catch up with the initial decline in revenue due to corruption, and, thus, equilibrate the budget. The drop in $\theta$ leads to a lower steady-state growth rate of output. In a similar way, with a large government size, increases in $\chi$ and $\lambda$ require a decline in $\theta$ for a balanced budget to be retained, followed by lower output growth. The increase in $\chi$ decreases the revenue side of equation (14), while the large and increasing size of $(1+\chi \varepsilon) \theta$ leads to greater expenses, even with a lower $b$. To restore budget equilibrium, a downward adjustment of $\theta$ is needed. Finally, an increase in $\lambda$, even though causes both sides of the budget to decline, with a large government size, revenue declines by more. This, in turn, calls for lower $\theta$. In sum, higher corruption in the presence of a large (small) government, leads to a downward (an upward) adjustment of the entire budget constraint and, thus, of public expenditure. This, in turn, reduces (raises) productivity and economic growth. This inverted-U curve type of effect implies that an optimal size of government can, in principle, be identified.

Proposition 3 is put to the test with numerical simulations. Panel $\mathrm{C}$ of Table 2 illustrates the effects of corruption on the share of public spending and on economic growth, when public spending is the only fiscal instrument that is allowed to vary. The findings support Corollary 3.1 for the case where the share of public spending as fraction of total GDP is relatively large, in that both endogenous variables decline in response to 
corruption. As in the previous propositions, the type of corruption that leads to greater declines in both $\theta$ and $\gamma$ is that associated with corruption in the collection of tax proceeds.

In general, these findings support the presence of non-linear effects of corruption on growth with the sign of the impact being contingent on the size of the government: corruption in an environment with a small government improves growth, while in a large government impedes growth. Even though the mechanism of transmission of these effects focuses purely on public spending considerations, other studies have unveiled conditional effects of corruption on growth by focusing on political institutional quality (Mendez and Sepulveda (2006), Meon and Sekkat (2005), and Aidt et al. (2008)). Studying interaction effects between corruption and government size in growth regressions could, therefore, be a worthwhile task.

\section{Corruption and growth with optimal (second-best) economic policy}

In the previous analysis, the role of the government has been "passive" in response to corruption, in the sense that its fiscal choices were determined by adjusting either the revenue or the expenditure side to ensure a balanced budget. This means that the government has not been choosing its instruments optimally in a way as to maximize some social welfare function. In this section, we examine whether the results obtained thus far in linking the key fiscal variables, corruption, and growth are robust to an approach that allows for the government to be "active" in its choices of fiscal instruments.

In this section, we endogenize economic policy as reflected by the optimal choice of the three fiscal instruments: $\theta^{*}, \tau^{*}$, and $R^{*}$. We assume a benevolent government that plays a Stackelberg leader vis-à-vis the private sector. This corresponds to the situation where agents make consumption-investment decisions by taking fiscal policy variables as given and then the government chooses fiscal instruments taking the response functions of agents as given. ${ }^{26}$ That is, the government maximizes the utility of the agents by

\footnotetext{
${ }^{26}$ An alternative approach would be to solve for the first-best (command-optimum) equilibrium where the benevolent government chooses the fiscal policy variables and consumption-investment decision rules at the same time. Aside from the fact that this approach is less realistic (since a government is unlikely to have control over private investment and consumption decisions), it should also be noted that the key
} 
considering its own budget and the market allocation as constraints, the latter being summarized by the growth rate equation (11). We assume commitment technologies on behalf of the government, so that decisions cannot be altered. ${ }^{27}$

To characterize the second-best equilibrium we use as objective of the benevolent government the sum of lifetime utilities of all agents over generations discounted by a factor $\rho, \rho \in(0,1)$, reflecting social time preference, expressed as ${ }^{28}$

$$
\Omega \equiv \sum_{t=0}^{\infty} \rho^{t} U_{t}
$$

where $U_{t}$ is the utility function given in equation (1). To ensure that $\Omega$ is bounded, we follow Barro (1990) in assuming $\rho<\gamma^{\sigma}$. Appendix B shows that the welfare criterion $\Omega$ corresponds to

$$
\Omega=-\frac{\left(b k_{-1}\right)^{-\sigma}}{\sigma\left(\gamma^{\sigma}-\rho\right)}\left[(1-\tau) \frac{\alpha}{\mu}\right]^{-\sigma} Y(R, r),
$$

where the growth rate $\gamma$ is described in equation (11) and

$$
Y(R, r) \equiv q^{1+\sigma}[R[1-\Delta(R, r)]]^{-\sigma}+(1-q)^{1+\sigma}[\beta b \Delta(R, r)]^{-\sigma}>0 .
$$

The term in square brackets of equation (15') represents the agents' income associated with legal practices, which is intermediated through financial corporations. This implies that social welfare depends only on the legal income of agents. The illegal income obtained through corrupt practices is not part of the government's welfare function, because the government knows the distribution of agents indulging in corrupt practices (even though it does not know a particular agent's type). Thus, the government abstracts

feature of our model is the existence of three different forms of corruption, which are exogenously given. Given that corruption is undetectable in our framework, a benevolent government has to choose its instruments appropriately while acknowledging that corruption does and will exist in equilibrium. In this context, the concept of an omniscient social planner that 'internalizes' corruption is difficult to fathom, and we therefore abstract from considerations of how a decentralized economy could replicate the social optimum (as, for example, could be studied when the services from public goods are affected by congestion), and focus on the government's second-best policy, which is termed the 'optimal' policy.

${ }^{27}$ Recent applications of this problem can be found in Park and Philippopoulos (2002), Espinosa-Vega and Yip (1999, 2002), and Chen (2006).

${ }^{28}$ We follow the conventional practice of ignoring the initial old people's utility in the evaluation of social welfare. 
entirely from the consideration of illegal income as part of its welfare function, revealing its aversion to illegitimate practices that allow corrupt bureaucrats to profit. Given the exogenous nature of corruption (in the aggregate), however, the government has to choose its fiscal instruments while acknowledging the distortions imposed by the presence of corrupt practices in attaining the second-best.

Solving the benevolent government's optimization problem, which amounts to maximizing equation (15') subject to equations (11) and (13) with respect to the three fiscal policy instruments $\left(\theta^{*}, \tau^{*}, R^{*}\right)$, it is established that the welfare-maximizing fiscal structure is determined by

$$
\begin{aligned}
& J_{1}\left(\tau^{*}, \theta^{*}, R^{*} ; \sigma, A, \alpha, \beta, \xi, \mu, \varepsilon, q, \rho, \eta, \chi, \lambda\right)=0, \\
& J_{2}\left(\tau^{*}, \theta^{*}, R^{*} ; \sigma, A, \alpha, \beta, \xi, \mu, \varepsilon, q, \rho, \eta, \chi, \lambda\right)=0,
\end{aligned}
$$

where the functions $J_{1}($.$) and J_{2}($.$) are defined in Appendix B. These two functions,$ along with the government budget constraint, are used to solve for $\left(\theta^{*}, \tau^{*}, R^{*}\right)$. In general, these being higher order polynomials, it is not possible to solve for the optimal budget instruments explicitly. For this reason, we resort to numerical simulations to solve for $\theta^{*}, \tau^{*}, R^{*}$, and in the process, also provide solutions to the rest of the endogenous variables $-b, r, \delta$, and $\gamma$ - with the use of equations (2'), (4), (10), and (11).

Using the values for the exogenous variables as listed earlier in Table 1, and choosing a value of 0.03 for the social welfare discount factor $(\rho)$, Table 3 presents the estimated values for the endogenous variables. A notable observation is that the size of all these variables is greater compared to their counterparts in Table 1 obtained under the decentralized equilibrium, except for the income tax rate which is lower. In particular, the government optimally taxes income at a rate of $10.05 \%$ and deflates prices at a gross rate of $3.88 \%$, with the combined collected revenue from income taxation and seigniorage being used to finance public sector wages and $21.89 \%$ of national income toward (net of corruption) productive public spending. Compared to the decentralized equilibrium, the larger value of $R$, despite implying a higher rate of return on money holdings, leads financial intermediaries to hold a larger share of their deposits in the form of capital assets. The higher value of $\delta$, in turn, along with the higher value of the output 
productivity of private capital, $b$, and the lower income tax rate, $\tau$, give rise to an economic growth rate $\gamma$ of $8.64 \%$.

These findings suggest that the government in maximizing welfare optimally selects a high inflation tax rate, which yields high revenue from seigniorage despite the lower inflation tax base, thus having to rely less on income taxation to sustain the financing of government expenditure. In essence, therefore, the government is trading off higher inflation taxes with lower income taxes. Thus, from a welfare perspective, the optimal policy represents an expansion of the money supply with a simultaneous contraction of the income tax rate.

Given our interest (i) in the effects of corruption on the fiscal instruments and on economic growth, and (ii) on whether these effects differ when the government is 'active' compared to 'passive' in its choice of these instruments, Table 4 presents comparative statics exercises that resemble in spirit to those performed in Table 2. That is, we track the behaviour of the policy variables and of economic growth once we allow each of the corruption parameters to change one at a time. But, unlike Table 2, and in order to capture the second-best, now all policy instruments are allowed to adjust simultaneously from their benchmark values in response to changes in corruption.

The simulations support two main results. First, every type of corruption leads the government to optimally reduce the level of productive spending and raise the income tax rate, while the rate of deflation declines in two of the three cases. In each case, the combined effect of these adjustments causes a lower growth rate of output, $\gamma$. Second, and most importantly, changes in the optimal fiscal instruments are in the same direction as those obtained in Table 2, under the government's 'passive' policy; the sole exception is the rise of $R$ in response to a change in $\chi^{29}$

With regard to the first finding, the government by being constrained in running a balanced budget in each period adjusts all its fiscal instruments, so as to increase its revenue and simultaneously decrease its expenditure, when corruption takes place. In this way, it tries to smooth out the effect of each form of corruption on all its instruments by minimizing their distortion to welfare. At the same time, these adjustments lead to lower

\footnotetext{
${ }^{29}$ All these comparative statics results are strongly confirmed via various sensitivity tests that use different changes in the magnitude of the corruption parameters. These alternative comparative statics are available upon request.
} 
economic growth, as would be expected. For example, starting from an initial equilibrium, a decrease in $\eta$ implies that a higher proportion of tax revenue is appropriated by corrupt bureaucrats, which forces the government to bring about a higher income tax rate and decrease both the optimal share of public expenditure and the optimal rate of return on holding money (i.e., higher inflation tax). These, in turn, lead to a decrease in both the growth rate and welfare.

The second main finding implies that a government that acts in such a way as to optimally choose its fiscal instruments in the presence of corruption leads to fiscal and economic changes that are in line with those under a government that adjusts its fiscal choices to run a balanced budget. Therefore, in connection with the growth and welfare effects of corruption, our findings show that it may not be critical whether the government takes a passive or an active stance in setting its fiscal variables in response to corruption. The qualitative similarity of the results under the two regimes underlines the robustness of the outcomes to different fiscal experiments in the presence of corruption. Although the implications for corruption on the growth rate are almost uniformly negative, our study shows how an optimising government could seek to prioritise its resources to reduce the types of corruption that harm growth more than others. For instance, in the context of tax revenue collection, the government could consider reforms in tax enforcement, which may include a bonus to the tax officer based on the amount of taxes he or she collects. This has been shown to bring about significant improvements in tax compliance (see, for example, Mookherjee (1995)). ${ }^{30}$

\section{Conclusion}

We observed at the outset the World Bank perception of corruption as a genuine threat to the efficient functioning of (mainly developing) economies, and its steely resolve to fight this evil by designing corruption-free institutions. Given the paramount importance of this issue, and given that a large proportion of corruption occurs through the public finances, we attempted to identify the various forms of bureaucratic corruption that are in existence, and the responses of a benevolent government in dealing with the same. More

\footnotetext{
${ }^{30}$ For an excellent analysis, and survey of the literature on incentives towards public officials, see Tirole (1994).
} 
specifically, this paper studied, via a unified analytical framework, the effects of corruption on an economy's growth rate, and on the policy instruments (income tax rate, inflation rate, and size of government spending) that are employed when bureaucratic corruption takes three forms: it reduces the tax revenues that are raised from households, inflates the volume of government spending, and reduces the productivity of effective government expenditure. Moreover, our analysis has distinguished between the case where fiscal choices are effectively determined exogenously through the balanced budget constraint, and the case where the government sets its instruments in an optimal manner to achieve the second-best policy outcome.

The effects of corruption on fiscal policy variables as well as growth are intuitive. Corruption reduces growth via higher income tax and inflation rates, and a lower level of government spending. Importantly, these transmission effects are valid and qualitatively similar under both a passive and an active stance by the government, which points to the robustness of our results. In this context, an optimising government would be able to identify the sources of corruption that have the most negative effects on an economy, and perhaps provide appropriate incentives to mitigate such corruption.

There is only one instance of corruption having a positive growth effect, and this is in the context of a government passively adjusting its level of expenditure in response to corruption. This result, however, depends on the size of the government, which needs to be relatively small to start with. If, on the other hand, the government is relatively large, corruption has a distorting growth effect. The nature of all these effects has not hitherto been explored in the literature. Moreover, our analysis - by combining the literature on corruption in public spending and finances with that on fiscal policy and growth - has established some results that could rationalise some of the findings in the earlier literature in the area.

Our research could be extended in different directions. One line of enquiry, which is outside the scope of the current exercise, would be to endogenize corruption by allowing a feedback effect from growth to corrupt activities. Indeed, some studies (Paldam (2002), Blackburn et al. (2006)) have suggested mechanisms via which such feedback is plausible. Such analysis would determine an equilibrium level of corruption and examine whether growth has different effects on the rewards to honesty and to 
corruption. Another area in which our research could be conducted would be to empirically estimate the effects of the different types of corruption in public expenditure and revenue on growth. This would supplement the work of Blackburn et al. (2010) on corruption on the revenue side of the government budget constraint. A third direction in which our research could be extended is to study the case where bond financing (rather than money financing) of deficits - along with tax financing - is considered feasible. This would be an interesting exercise in the context of countries where corruption is rife, and which operate under the Stability and Growth Pact, that assigns upper limits to deficits and debt, and virtually rules out seigniorage.

\section{References}

Acemoglu, D. (1995). "Reward Structures and the Allocation of Talent." European Economic Review, 39, 17-33.

Acemoglu, D., and T. Verdier (2000). "The Choice Between Market Failures and Corruption." American Economic Review, 90, 194-211.

Adam, C.S., and D.L. Bevan (2005). "Fiscal Deficits and Growth in Developing Countries." Journal of Public Economics, 89, 571-597.

Aidt, T., J. Dutta, and V. Sena (2008). "Governance Regimes, Corruption and Growth: Theory and Evidence." Journal of Comparative Economics, 36, 195-220.

Al-Marhubi, F.A. (2000). "Corruption and Inflation." Economics Letters, 66, 199-202.

Bandeira, A.C., F. Garcia, and M.F.G. da Silva (2001). "How does Corruption Hurt Growth? Evidences about the Effects of Corruption on Factors Productivity and Per Capita Income." Escola de Economia de São Paulo Discussion Paper No. 103, University of Sao Paolo.

Bardhan, P. (1997). "Corruption and Development: A Review of the Issues." Journal of Economic Literature, 35, 1320-1346.

Barreto, R. (2000). "Endogenous Corruption in a Neoclassical Growth Model." European Economic Review, 44(1), 35-60.

Barro, R. J. (1990). "Government Spending in a Simple Model of Endogenous Growth." Journal of Political Economy, 98, S103-25.

Barro, R. J., and X. Sala-i-Martin (1995). Economic Growth. NewYork: McGraw-Hill.

Baxter, M. and R. G. King (1993). "Fiscal Policy in General Equilibrium." American Economic Review, 83(3), 315-334.

Bencivenga, V. and B.D. Smith (1993). "Some Consequences of Credit Rationing in an Endogenous Growth Model." Journal of Economic Dynamics and Control, 17, 97122.

Bird, R. M. and E. M. Zolt (2005). "The Limited Role of the Personal Income Tax in Developing Countries." Journal of Asian Economics, 16, 928-46. 
Blackburn, K., N. Bose, and M. E. Haque (2006). "The Incidence and Persistence of Corruption in Economic Development." Journal of Economic Dynamics and Control, 30, 2447-67.

Blackburn, K., K.C. Neanidis, and M. E. Haque (2010). "Corruption, Seigniorage and Growth: An Empirical Investigation." Unpublished Manuscript, University of Manchester.

Bose, N., J.A. Holman, and K.C. Neanidis (2007). "The Optimal Public Expenditure Financing Policy: Does the Level of Economic Development Matter?" Economic Inquiry, 45, 433-452.

Boycko, M., A. Shleifer, and R. Vishny (1995). Privatizing Russia, MIT Press, Cambridge, MA.

Chen, B-.L. (2006). "Economic Growth with an Optimal Public Spending Composition." Oxford Economic Papers, 58, 123-136.

Cukierman, A., S. Edwards, and G. Tabellini (1992). "Seigniorage and Political Instability." American Economic Review, 82, 537-555.

Dar, A. and S. AmirKhalkhali (2002). "Government Size, Factor Accumulation, and Economic Growth: Evidence from OECD Countries." Journal of Policy Modeling, 24, 679-92.

De Gregorio, J. (1993). "Inflation, Taxation, and Long-Run Growth." Journal of Monetary Economics, 31, 271-98.

Del Monte, A., and E. Papagni (2001). "Public Expenditure, Corruption and Economic Growth: The Case of Italy." European Journal of Political Economy, 17, 1-16.

Diamond, D., and P. Dybvig (1983). "Bank Runs, Deposit Insurance and Liquidity." Journal of Political Economy, 85, 191-206.

Ehrlich, I., and F.T. Lui (1999). "Bureaucratic Corruption and Endogenous Economic Growth." Journal of Political Economy, 107, 270-293.

Ellis, C.J., and J. Fender (2006). "Corruption and Transparency in a Growth Model." International Tax and Public Finance, 13, 115-49.

Espinosa-Vega, M.A., and C.K. Yip (1999). "Fiscal and Monetary Policy Interactions in an Endogenous Growth Model with Financial Intermediaries." International Economic Review, 40, 595-615.

Espinosa-Vega, M.A., and C.K. Yip (2002). "Government Financing in an Endogenous Growth Model with Financial Market Restrictions.” Economic Theory, 20, 237-257.

Faruq, H., M. Webb, and D. Yi (2013). "Corruption, Bureaucracy and Firm Productivity in Africa." Review of Development Economics, 17(1), 117-129.

Gallagher, M. (2005). "Benchmarking Tax Systems." Public Administration and Development, 25, 125-44.

Ghosh, S., and A. Gregoriou (2008). "The Composition of Government Spending and Growth: Is Current or Capital Spending Better?" Oxford Economic Papers, 60(3), 484516.

Hall, R.E., and C. Jones (1999). "Why Do Some Countries Produce So Much More Output per Worker than Others?" Quarterly Journal of Economics, 114, 83-116.

Hillman, Arye L. (2004). "Corruption and public finance: an IMF perspective." European Journal of Political Economy, 20, 1067-77. 
Holman, J.A. and K.C. Neanidis (2006). "Financing Government Expenditures in an Open Economy." Journal of Economic Dynamics and Control, 30, 1315-37.

Huntington, S.P. (1968) Political Order in Changing Societies. Yale University Press, New Haven, CT.

Imam, P.A., and D.F. Jacobs (2007). "Effect of Corruption on Tax Revenues in the Middle East." Working Paper No.270, International Monetary Fund.

Ivanyna, M., A. Mourmouras, and P. Rangazas (2016). "The Culture of Corruption, Tax Evasion, and Economic Growth.” Economic Inquiry, 54(1), 520-542.

Ivanyna, M., A. Mourmouras, and P. Rangazas (2015). "Corruption, Public Debt, Economic Growth.” Unpublished Manuscript, Michigan State University.

Krueger, A.O. (1974). "The Political Economy of the Rent-Seeking Society." American Economic Review, 64, 291-303.

Lambsdorff, J.G. (2003). "How Corruption Affects Productivity." Kyklos, 56, 457-474.

Leff, N.H. (1964). "Economic Development through Bureaucratic Corruption." American Behavioural Scientist, 8, 8-14.

Litina, A., and T. Palivos (2016). "'Corruption, Tax Evasion and Social Values." Journal of Economic Behavior and Organization, 124, 164-177.

Lui, F.T. (1985). "An Equilibrium Queuing Model of Bribery." Journal of Political Economy, 93, 760-781.

Mauro, P. (1995). "Corruption and Growth." Quarterly Journal of Economics, 110, 681-712.

Mauro, P. (2004). "The Persistence of Corruption and Slow Economic Growth." IMF Staff Papers, 51, 1-18.

Méndez, F., and F. Sepúlveda (2006). "Corruption, Growth and Political Regimes: Cross Country Evidence." European Journal of Political Economy, 22, 82-98.

Meon, P-G. and K. Sekkat (2005). "Does Corruption Grease or Sand the Wheels of Growth?" Public Choice, 122, 69-97.

Miller, S., and F. Russek (1997). "Fiscal Structures and Economic Growth: International Evidence." Economic Inquiry, 35, 603-613.

Mookherjee, D. (1995) "Reforms in Income Tax Enforcement in Mexico." IRIS-India Working Paper No.6. University of Maryland.

Murphy, K., A. Shleifer, and R. Vishny (1993). "Why is rent-seeking so costly to growth?” American Economic Review, 83, 409-414.

Murphy, K., A. Shleifer, and R. Vishny (1991). "The Allocation of Talent: Implications for Growth." Quarterly Journal of Economics, 106, 503-530.

Myles, G.D., and H. Yousefi (2015). "Corruption and Seigniorage", Journal of Public Economic Theory, 17(4), 480-503.

Olson, M., Sarna, N. Swamy, Anand V. (2000). "Governance and Growth: A Simple Hypothesis Explaining Cross-Country Differences in Productivity Growth." Public Choice, 102 (3-4), 341-364.

O'Toole, C.M. and F. Tarp (2014). "Corruption and the Efficiency of Capital Investment in Developing Countries." Journal of International Development, (forthcoming).

Paldam, M. (2002). "The Cross-Country Pattern of Corruption: Economics, Culture and the Seesaw Dynamics." European Journal of Political Economy, 18(2), 215-240. 
Palivos, T. and C.K. Yip (1995). "Government Expenditure Financing in an Endogenous Growth Model: A Comparison." Journal of Money, Credit, and Banking, 27, 1159-78.

Park, H. and A. Philippopoulos (2002). "Dynamics of Taxes, Public Services, and Endogenous Growth.” Macroeconomic Dynamics, 6, 187-201.

Romer, P. (1994). "New goods, old theory, and the welfare costs of trade restrictions." Journal of Development Economics, 43, 5-38.

Rose-Ackerman, S. (1999). Corruption and Government: Causes, Consequences and Reforms. Cambridge University Press, Cambridge.

Roubini, N. and X. Sala-i-Martin (1995). "A Growth Model of Inflation, Tax Evasion, and Financial Repression." Journal of Monetary Economics, 35, 275-301.

Salinas-Jimenez, M.d.M. and J. Salinas-Jimenez (2007). "Corruption, Efficiency and Productivity in OECD Countries.” Journal of Policy Modeling, 29, 903-15.

Sarte, P.D. (2000). "Informality and Rent-Seeking Bureaucracies in a Model of LongRun Growth.” Journal of Monetary Economics, 46, 173-197.

Shleifer, A. and R.W. Vishny (1993). "Corruption." Quarterly Journal of Economics, 108, 599-617.

Svensson, J. (2005). "Eight Questions about Corruption." Journal of Economic Perspectives, 19, 19-42.

Tanzi, V., and H.R. Davoodi (1997). "Corruption, Public Investment, and Growth." IMF Working Paper No. 139, International Monetary Fund.

Tanzi, V., and H.R. Davoodi (2000). "Corruption, Growth, and Public Finances." IMF Working Paper No. 182, International Monetary Fund.

Tirole, J. (1994). "The Internal Organization of Government." Oxford Economic Papers, 46, 1-29.

Turnovsky, S. J. (2004). "The Transitional Dynamics of Fiscal Policy: Long-Run Capital Accumulation and Growth." Journal of Money, Credit and Banking, 36, 883910.

Treisman, D. (2000). “The Causes of Corruption: A Cross-National Study." Journal of Public Economics, 76, 399-457.

Wei, S-J. (1997). ). "Why is Corruption so Much More Taxing than Tax? Arbitrariness Kills." NBER Working Paper No. 6255, National Bureau of Economic Research.

World Bank (1989). World Development Report, Oxford University Press, New York, NY.

Acknowledgements: We would like to thank participants at the 2014 Royal Economic Society Annual Conference in Manchester, where this paper was presented, and an anonymous referee for insightful comments and constructive suggestions. The usual disclaimer applies. 


\section{Appendices}

$\mathbf{A}(\mathbf{I})$.

Under the assumptions of $d \theta=0$ and $d \tau=0$, the matrix form expression of equations (11') and (13') is

$$
\left[\begin{array}{ll}
a_{11} & a_{12} \\
a_{21} & a_{22}
\end{array}\right]\left[\begin{array}{l}
d \gamma \\
d R
\end{array}\right]=\left[\begin{array}{lll}
a_{13} & a_{14} & a_{15} \\
a_{23} & a_{24} & a_{25}
\end{array}\right]\left[\begin{array}{l}
d \eta \\
d \chi \\
d \lambda
\end{array}\right],
$$

where $\quad a_{11}=1>0, \quad a_{12}=-\frac{(1-\tau) \alpha b}{\mu} \frac{\partial \Delta}{\partial R}<0, \quad a_{13}=0, \quad a_{14}=\frac{(1-\tau) \alpha \Delta}{\mu} \frac{1+\sigma \Delta}{1+\sigma} \frac{\partial b}{\partial \chi}<0$, $a_{15}=\frac{(1-\tau) \alpha \Delta}{\mu} \frac{1+\sigma \Delta}{1+\sigma} \frac{\partial b}{\partial \lambda}<0, \quad a_{21}=\frac{1}{b} \frac{1-\Delta}{\Delta}>0, \quad a_{22}=-\left[\frac{1-\Delta}{\Delta}+(\gamma-R) \frac{1}{\Delta^{2}} \frac{\partial \Delta}{\partial R}\right] \frac{1}{b}<0$, $a_{23}=-\frac{\alpha}{\mu} \tau<0, a_{24}=\theta \varepsilon+(\gamma-R) \frac{1}{\Delta} \frac{1}{b^{2}} \frac{1-\Delta}{1+\sigma} \frac{\partial b}{\partial \chi}$, and $a_{25}=(\gamma-R) \frac{1}{\Delta} \frac{1}{b^{2}} \frac{1-\Delta}{1+\sigma} \frac{\partial b}{\partial \lambda}<0$.

In obtaining the signs of $a_{14}, a_{15}, a_{24}$, and $a_{25}$, we have used equation (4) and the expression of $b$ from the output per capita equation (2'), from where it can be shown that $\partial b / \partial \chi<0$ and $\partial b / \partial \lambda<0$.

Using equation (A1), we can derive the inflation and growth effects of a change in corruption related with the collection of tax revenues; that is, of a lower $\eta$. These are

$$
\begin{aligned}
& \frac{d R}{d \eta}=\frac{a_{11} a_{23}-a_{21} a_{13}}{\operatorname{Det}} \\
& \frac{d \gamma}{d \eta}=\frac{a_{13} a_{22}-a_{23} a_{12}}{\operatorname{Det}}
\end{aligned}
$$

where 'Det' is the determinant, for which the expression is provided in equation (A9) below. 
Using equation (A1) again, we can derive the inflation and growth effects of a change in corruption related with the procurement of public goods; that is, of a higher $\chi$. These are

$$
\begin{aligned}
& \frac{d R}{d \chi}=\frac{a_{11} a_{24}-a_{21} a_{14}}{D e t}, \\
& \frac{d \gamma}{d \chi}=\frac{a_{14} a_{22}-a_{24} a_{12}}{D e t},
\end{aligned}
$$

Finally, using equation (A1) we can derive the inflation and growth effects of a change in corruption related with the productivity of public goods; that is, of a higher $\lambda$, as

$$
\begin{aligned}
& \frac{d R}{d \lambda}=\frac{a_{11} a_{25}-a_{21} a_{15}}{D e t}, \\
& \frac{d \gamma}{d \lambda}=\frac{a_{15} a_{22}-a_{25} a_{12}}{\text { Det }}
\end{aligned}
$$

In equations (A2)-(A7) the determinant is given by

$$
\text { Det }=a_{11} a_{22}-a_{21} a_{12}=-\left[\frac{1-\Delta}{\Delta}+(\gamma-R) \frac{1}{\Delta^{2}} \frac{\partial \Delta}{\partial R}-\frac{1-\Delta}{\Delta} \frac{1}{\Delta} \frac{\partial \Delta}{\partial R} \gamma\right] \frac{1}{b} .
$$

Using equation (10), we find

$$
\frac{\partial \Delta}{\partial R}=\frac{\Delta}{R} \frac{\sigma}{1+\sigma} \frac{1}{1+\left(\frac{q}{1-q}\right)\left(\frac{R}{r}\right)^{\frac{\sigma}{1+\sigma}}}>0 .
$$

So, the determinant becomes

$$
D e t=-\frac{1}{b} \frac{1}{\Delta} \frac{1}{1+\sigma} \frac{1+\sigma \Delta \frac{\gamma}{R}}{1+\left(\frac{q}{1-q}\right)\left(\frac{R}{r}\right)^{\frac{\sigma}{1+\sigma}}}<0 .
$$

Using equation (A9) along with the expressions for $a_{i j}$ defined above into the pairs of equations (A2)-(A3), (A4)-(A5), and (A6)-(A7) respectively, we obtain that $d R / d \eta>0$, $d \gamma / d \eta>0, d R / d \chi<0, d \gamma / d \chi<0, d R / d \lambda<0$, and $d \gamma / d \lambda<0$, which form the basis for Proposition 1.

\section{A(II).}

Under the assumptions of $d \theta=0$ and $d R=0$, the new matrix form expression for the set of equations (11') and (13') now is 


$$
\left[\begin{array}{ll}
b_{11} & b_{12} \\
b_{21} & b_{22}
\end{array}\right]\left[\begin{array}{l}
d \gamma \\
d \tau
\end{array}\right]=\left[\begin{array}{lll}
b_{13} & b_{14} & b_{15} \\
b_{23} & b_{24} & b_{25}
\end{array}\right]\left[\begin{array}{l}
d \eta \\
d \chi \\
d \lambda
\end{array}\right],
$$

where $b_{i j}=a_{i j}$ except for $b_{12}=\frac{\alpha b}{\mu} \Delta>0$ and $b_{22}=\frac{\eta \alpha}{\mu}>0$.

Using equation (A10), we can derive the income tax rate and growth effects of a change in corruption related with the collection of tax revenues; that is, of a lower $\eta$. These are

$$
\begin{aligned}
& \frac{d \tau}{d \eta}=\frac{b_{11} b_{23}-b_{21} b_{13}}{D E T}, \\
& \frac{d \gamma}{d \eta}=\frac{b_{13} b_{22}-b_{23} b_{12}}{D E T},
\end{aligned}
$$

where 'DET' is the determinant, for which the expression is provided in equation (A17) below.

Using equation (A10) again, we can derive the income tax rate and growth effects of a change in corruption related with the procurement of public goods; that is, of a higher $\chi$. These are

$$
\begin{aligned}
& \frac{d \tau}{d \chi}=\frac{b_{11} b_{24}-b_{21} b_{14}}{D E T}, \\
& \frac{d \gamma}{d \chi}=\frac{b_{14} b_{22}-b_{24} b_{12}}{D E T},
\end{aligned}
$$

Finally, using equation (A10) we can derive the income tax rate and growth effects of a change in corruption related with the productivity of public goods; that is, of a higher $\lambda$, as

$$
\begin{aligned}
& \frac{d \tau}{d \lambda}=\frac{b_{11} b_{25}-b_{21} b_{15}}{D E T}, \\
& \frac{d \gamma}{d \lambda}=\frac{b_{15} b_{22}-b_{25} b_{12}}{D E T},
\end{aligned}
$$

In equations (A11)-(A16) the determinant is given by ${ }^{31}$

$$
D E T=b_{11} b_{22}-b_{21} b_{12}=b_{22}=\eta+\Delta-1>0 .
$$

Using equation (A17) along with the expressions for $b_{i j}$ defined above into the pairs of equations (A11)-(A12), (A13)-(A14), and (A15)-(A16) respectively, we obtain that

\footnotetext{
${ }^{31}$ The positive sign of the determinant is proved in Appendix B below.
} 
$d \tau / d \eta<0, d \gamma / d \eta>0, d \tau / d \chi>0, d \gamma / d \chi<0, d \tau / d \lambda>0$, and $d \gamma / d \lambda<0$, which form the basis for Proposition 2.

\section{A(III).}

Using the restrictions that $d \tau=0$ and $d R=0$, the new matrix form expression for the set of equations (11') and (13') now is

$$
\left[\begin{array}{ll}
c_{11} & c_{12} \\
c_{21} & c_{22}
\end{array}\right]\left[\begin{array}{l}
d \gamma \\
d \theta
\end{array}\right]=\left[\begin{array}{lll}
c_{13} & c_{14} & c_{15} \\
c_{23} & c_{24} & c_{25}
\end{array}\right]\left[\begin{array}{l}
d \eta \\
d \chi \\
d \lambda
\end{array}\right],
$$

where $\quad c_{i j}=a_{i j} \quad$ except $\quad$ for $\quad c_{12}=-\frac{(1-\tau) \alpha \Delta}{\mu} \frac{1+\sigma \Delta}{1+\sigma} \frac{\partial b}{\partial \theta}<0 \quad$ and $c_{22}=-\left[1+\chi \varepsilon+(\gamma-R) \frac{1}{\Delta} \frac{1}{b^{2}} \frac{1-\Delta}{1+\sigma} \frac{\partial b}{\partial \theta}\right]<0$.

Using equation (A18), we can derive the effects of a change in corruption associated with the collection of tax revenues (a lower $\eta$ ) on government expenditure and growth. These are

$$
\begin{aligned}
& \frac{d \theta}{d \eta}=\frac{c_{11} c_{23}-c_{21} c_{13}}{D e t^{\prime}}, \\
& \frac{d \gamma}{d \eta}=\frac{c_{13} c_{22}-c_{23} c_{12}}{D e t^{\prime}},
\end{aligned}
$$

where 'Det' is the determinant, for which the expression is provided in equation (A25) below.

Using equation (A18) again, we can derive the effects of a change in corruption associated with the procurement of public goods (a higher $\chi$ ) on government expenditure and growth. These are

$$
\begin{aligned}
& \frac{d \theta}{d \chi}=\frac{c_{11} c_{24}-c_{21} c_{14}}{D e t^{\prime}}, \\
& \frac{d \gamma}{d \chi}=\frac{c_{14} c_{22}-c_{24} c_{12}}{D e t^{\prime}},
\end{aligned}
$$

Finally, using equation (A18) we can derive the effects of a change in corruption associated with the productivity of public goods (a higher $\lambda$ ) on government expenditure and growth. These are 


$$
\begin{aligned}
& \frac{d \theta}{d \lambda}=\frac{c_{11} c_{25}-c_{21} c_{15}}{D e t^{\prime}}, \\
& \frac{d \gamma}{d \lambda}=\frac{c_{15} c_{22}-c_{25} c_{12}}{D e t^{\prime}},
\end{aligned}
$$

In equations (A19)-(A24) the determinant is given by

$$
\text { Det }^{\prime}=c_{11} c_{22}-c_{21} c_{12}=R \frac{1-\Delta}{\Delta} \frac{1}{b^{2}} \frac{\partial b}{\partial \theta}-(1+\chi \varepsilon) .
$$

Multiplying and dividing through equation (A25) by $\theta$, and using equations (2'), (5) and that $\partial b / \partial \theta=(1-\beta / \beta)(b / \theta)$, yields

$$
D^{\prime} t^{\prime}=\frac{1}{\theta}\left[\frac{R+\gamma \sigma \Delta}{1+\sigma} \frac{1}{b} \frac{1-\Delta}{\Delta} \frac{1-\beta}{\beta}-\frac{g}{y}\right],
$$

the sign of which is in general ambiguous. The sign depends on the relative size of total spending on public goods and services (as a fraction of GDP). If this ratio is large, then Det' $<0$ and the effects captured by equations (A19)-(A24) can be assigned the following signs: $d \theta / d \eta>0, d \gamma / d \eta>0, d \theta / d \chi<0, d \gamma / d \chi<0, d \theta / d \lambda<0$, and $d \gamma / d \lambda<0$. If $g / y$ is relatively small, the opposite effects take shape. These findings form the basis for Corollary 3.1.

\section{B.}

The economy is populated by two types of agents, households and bureaucrats, of which bureaucrats are divided into those that oversee the collection of tax revenue and those that deal with the procurement of the public good. In these two classes of bureaucrats, there are in place both honest and corrupt public officials. This description of the structure of our economy shows that there is no such thing as one representative agent. Therefore, when the benevolent government is deriving the welfare criterion, $\Omega$ in equation (15), it takes into account the discounted lifetime utility of all agents. Given that utility is solely based on consumption during the second period of the agents' lives, the appropriate measure of welfare is a function of the total level of consumption in the economy during the agents' lifetime.

The income of households and the legal income of bureaucrats are saved with the financial intermediaries, while the illegal income of bureaucrats is saved "under the mattress." This means that only the income saved through banks is subject to an uncertain rate of return conditional on the probability of the agent's relocation. The illegal income, on the other hand, carries no rate of return. This latter income is represented by the total amount appropriated by corrupt bureaucrats: $(1-\mu)\left[(1-\eta) \tau w_{t}+\chi \varepsilon \theta_{t}\right]$. This illegal income, however, is not included in the government's social welfare function given that the government knows the proportion of corrupt bureaucrats, and thus the size of their 
income. In other words, the government considers in its welfare function only consumption that arises from legal income.

From equations (15), (1), and (7), the benevolent government maximizes

$$
\Omega \equiv \sum_{t=0}^{\infty} \rho^{t} U_{t}
$$

where

$$
U_{t}=-q \frac{\left[(1-\tau) w_{t} i_{t}\right]^{-\sigma}}{\sigma}-(1-q) \frac{\left[(1-\tau) w_{t} I_{t}\right]^{-\sigma}}{\sigma}
$$

subject to the economic growth rate equation (11) and the government budget constraint equation (13), which we re-write both here for convenience

$$
\begin{gathered}
\gamma=\frac{(1-\tau) \alpha b}{\mu} \Delta(R, r), \\
\left(\frac{\gamma-R}{b}\right)\left[\frac{1-\Delta(R, r)}{\Delta(R, r)}\right]+\eta \frac{\alpha}{\mu} \tau=(1+\chi \varepsilon) \theta+\frac{(1-\mu) \alpha}{\mu} .
\end{gathered}
$$

Using equations (2'), (3), (4), (8), and (9) into equation (B2), the latter becomes

$$
U_{t}=-\frac{1}{\sigma}\left\{q\left[(1-\tau) \frac{\alpha}{\mu} \frac{R}{q}[1-\Delta(R, r)]\right]^{-\sigma}+(1-q)\left[(1-\tau) \frac{\alpha}{\mu} \frac{\beta b}{1-q} \Delta(R, r)\right]^{-\sigma}\right\}\left(b k_{t}\right)^{-\sigma}
$$

or,

$$
U_{t}=-\frac{1}{\sigma}\left\{\left[(1-\tau) \frac{\alpha}{\mu}\right]^{-\sigma} Y(R, r)\right\}\left(b k_{t}\right)^{-\sigma}
$$

where $^{32}$

$$
Y(R, r) \equiv q^{1+\sigma}[R[1-\Delta(R, r)]]^{-\sigma}+(1-q)^{1+\sigma}[\beta b \Delta(R, r)]^{-\sigma}>0 .
$$

Using equation (B2') and the growth rate equation (B3), some algebra reveals that equation (B1) becomes equation (15'), or

\footnotetext{
${ }^{32}$ Tedious calculations reveal that

$\partial Y / \partial R \equiv-\frac{\sigma}{1+\sigma} \frac{1}{R}\left\{\sigma[1-\Delta(R, r)] Y(R, r)+q^{1+\sigma}[R[1-\Delta(R, r)]]^{-\sigma}\right\}<0$ and

$\partial Y / \partial \theta \equiv-\frac{\sigma}{1+\sigma} \frac{1-\beta}{\beta} \frac{1}{\theta}\left\{\sigma \Delta(R, r) Y(R, r)+(1-q)^{1+\sigma}[\beta b \Delta(R, r)]^{-\sigma}\right\}<0$.
} 


$$
\Omega=-\frac{\left(b k_{-1}\right)^{-\sigma}}{\sigma\left(\gamma^{\sigma}-\rho\right)}\left\{\left[(1-\tau) \frac{\alpha}{\mu}\right]^{-\sigma} Y(R, r)\right\} .
$$

Solving for the benevolent government's optimization problem, which amounts to maximizing equation (B5) subject to equations (B3) and (B4) with respect to the three fiscal policy instruments $(\tau, \theta$, and $R$ ), the optimality conditions are given respectively by

$$
\begin{gathered}
\Omega \sigma\left(\frac{1}{1-\tau}\right)\left(\frac{2 \gamma^{\sigma}-\rho}{\gamma^{\sigma}-\rho}\right)+\lambda\left(\frac{\alpha}{\mu}\right)(1-\Delta-\eta)=0, \\
-\Omega \sigma\left(\frac{1-\beta}{\beta}\right)\left(\frac{1}{\theta}\right)\left\{\left(\frac{1}{\gamma^{\sigma}-\rho}\right)\left[\gamma^{\sigma}\left(\frac{2+\sigma(1+\Delta)}{1+\sigma}\right)-\rho\right]\right\}- \\
-\Omega \sigma\left(\frac{1-\beta}{\beta}\right)\left(\frac{1}{\theta}\right)\left\{\left(\frac{1}{Y}\right)\left(\frac{1}{1+\sigma}\right)\left[\sigma \Delta Y+(1-q)^{1+\sigma}(\beta b \Delta)^{-\sigma}\right]\right\}+ \\
+\left\{1+\chi \varepsilon-\left(\frac{1-\Delta}{\Delta}\right)\left(\frac{1}{b}\right)\left(\frac{1-\beta}{\beta}\right)\left(\frac{1}{\theta}\right)\left(\frac{1}{1+\sigma}\right)(R+\gamma \sigma \Delta)\right\}=0, \\
-\Omega \sigma\left\{\left(\frac{\sigma \gamma^{\sigma}}{\gamma^{\sigma}-\rho}\right)(1-\Delta)+\left(\frac{1}{Y}\right)\left[\sigma(1-\Delta) Y+q^{1+\sigma}[R(1-\Delta)]-\sigma\right]\right\}+ \\
+\lambda\left(\frac{1}{b}\right)\left(\frac{1-\Delta}{\Delta}\right)(R+\gamma \sigma \Delta)=0,
\end{gathered}
$$

where $\lambda$ is the Lagrange multiplier associated with the government budget constraint and $\partial \Delta / \partial R$ and $\partial Y / \partial R$ are as defined in the text. ${ }^{33}$

Next, combining equations (B6) and (B7), and simplifying, yields

$$
\begin{gathered}
\left(\frac{1}{1-\tau}\right)\left(\frac{2 \gamma^{\sigma}-\rho}{\gamma^{\sigma}-\rho}\right)\left\{1+\chi \varepsilon-\left(\frac{1-\Delta}{\Delta}\right)\left(\frac{1}{b}\right)\left(\frac{1-\beta}{\beta}\right)\left(\frac{1}{\theta}\right)\left(\frac{1}{1+\sigma}\right)(R+\gamma \sigma \Delta)\right\}= \\
-\left(\frac{\alpha}{\mu}\right)(1-\Delta-\eta)\left(\frac{1-\beta}{\beta}\right)\left(\frac{1}{\theta}\right)\left\{\left(\frac{1}{\gamma^{\sigma}-\rho}\right)\left[\gamma^{\sigma}\left(\frac{2+\sigma(1+\Delta)}{1+\sigma}\right)-\rho\right]\right\}- \\
-\left(\frac{\alpha}{\mu}\right)(1-\Delta-\eta)\left(\frac{1-\beta}{\beta}\right)\left(\frac{1}{\theta}\right)\left\{\left(\frac{1}{Y}\right)\left(\frac{1}{1+\sigma}\right)\left[\sigma \Delta Y+(1-q)^{1+\sigma}(\beta b \Delta)^{-\sigma}\right]\right\}+,
\end{gathered}
$$

while combining equations (B6) and (B8), yields

\footnotetext{
${ }^{33}$ Given the restriction $\rho<\gamma^{\sigma}$, equation (B6) implies that $1-\Delta-\eta<0$. This, in turn, proves the positive sign of the determinant identified in equation (A17) in Appendix (AII) above.
} 


$$
\begin{gathered}
\left(\frac{1}{1-\tau}\right)\left(\frac{2 \gamma^{\sigma}-\rho}{\gamma^{\sigma}-\rho}\right)\left(\frac{1-\Delta}{\Delta}\right)\left(\frac{1}{b}\right)(R+\gamma \sigma \Delta)= \\
-\left(\frac{\alpha}{\mu}\right)(1-\Delta-\eta)\left\{\left(\frac{\sigma \gamma^{\sigma}}{\gamma^{\sigma}-\rho}\right)(1-\Delta)+\left(\frac{1}{Y}\right)\left[\sigma(1-\Delta) Y+q^{1+\sigma}[R(1-\Delta)]^{-\sigma}\right]\right\} .
\end{gathered}
$$

These two reduced optimality conditions, (B9) and (B10), which define the two implicit functions $J_{1}($.$) and J_{2}$ (.) in the text, along with the government budget constraint (13), are used to solve for the three (second-best) optimal fiscal instruments, $\theta^{*}, \tau^{*}$, and $R^{*}$. These expressions, however, are highly non-linear, and as a result explicit solutions for the optimal fiscal instruments, and of the effects of corruption, cannot be obtained. For this reason, we rely on numerical simulations, as discussed in the text.

Table 1

\begin{tabular}{|c|c|c|}
\hline Exogenous variables & Value & Definition \\
\hline $\bar{\sigma}$ & 10 & $\begin{array}{l}\sigma=\frac{1}{I E S}-1, \text { where IES is the } \\
\text { intertemporal elasticity of } \\
\text { substitution. }\end{array}$ \\
\hline$A$ & 2 & Firm's total factor productivity \\
\hline$\alpha$ & 0.67 & $\begin{array}{l}\text { Elasticity of output with respect to } \\
\text { labour }\end{array}$ \\
\hline$\beta$ & 0.55 & $\begin{array}{l}\text { Elasticity of output with respect to } \\
\text { private capital }\end{array}$ \\
\hline$\xi$ & 0.7 & $\begin{array}{l}\text { Public goods productivity in firm's } \\
\text { output }\end{array}$ \\
\hline$q$ & 0.55 & $\begin{array}{l}\text { Probability of agent relocation in } \\
\text { second period of life }\end{array}$ \\
\hline$\rho$ & 0.03 & Social welfare discount factor \\
\hline$\mu$ & 0.8 & Share of households in economy \\
\hline$\varepsilon$ & 0.025 & $\begin{array}{l}\text { Size of public spending inflated } \\
\text { due to corruption }\end{array}$ \\
\hline \multicolumn{3}{|l|}{ Corruption variables } \\
\hline$\eta$ & 0.95 & $\begin{array}{l}\text { Proportion of non-corrupt } \\
\text { bureaucrats in charge of public } \\
\text { revenue collection }\end{array}$ \\
\hline$\chi$ & 0.25 & $\begin{array}{l}\text { Proportion of corrupt bureaucrats } \\
\text { in charge of public good } \\
\text { procurement }\end{array}$ \\
\hline$\lambda$ & 0.5 & $\begin{array}{l}\text { Productivity loss of public } \\
\text { spending due to bureaucrat corrupt }\end{array}$ \\
\hline
\end{tabular}

Benchmark Parameters 
practices

Endogenous variables

\begin{tabular}{|c|c|c|}
\hline$r$ & 0.2652 & $\begin{array}{l}\text { Real rate of return on capital } \\
\text { holdings (MPK) }\end{array}$ \\
\hline$b$ & 0.4821 & $\begin{array}{l}\text { Linear output productivity of } \\
\text { private capital }\end{array}$ \\
\hline$\delta$ & 0.1442 & $\begin{array}{l}\text { Fraction of bank deposits lent to } \\
\text { firms }\end{array}$ \\
\hline$R$ & 0.03 & $\begin{array}{l}\text { Real rate of return on money } \\
\text { holdings }\end{array}$ \\
\hline 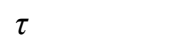 & 0.2683 & Income (wage) tax rate \\
\hline$\theta$ & 0.2 & $\begin{array}{l}\text { Proportion of output toward public } \\
\text { goods expenditure }\end{array}$ \\
\hline$\gamma$ & 0.0426 & $\begin{array}{l}\text { Equilibrium growth rate of output } \\
\text { per capita }\end{array}$ \\
\hline
\end{tabular}

Table 2

Comparative Statics Exercises of Passive Government Policy

\begin{tabular}{|c|c|c|c|c|}
\hline & $\theta$ & $\tau$ & $\boldsymbol{R}$ & $\gamma$ \\
\hline Benchmark values & 0.2 & 0.2683 & 0.03 & 0.0426 \\
\hline \multicolumn{5}{|l|}{ Panel A: Proposition 1} \\
\hline$\eta: 0.95 \rightarrow 0.9$ & 0.2 & 0.2683 & 0.0268 & 0.0390 \\
\hline$\chi: 0.25 \rightarrow 0.3$ & 0.2 & 0.2683 & 0.0292 & 0.0415 \\
\hline$\lambda: 0.5 \rightarrow 0.55$ & 0.2 & 0.2683 & 0.0296 & 0.0421 \\
\hline \multicolumn{5}{|l|}{ Panel B: Proposition 2} \\
\hline$\eta: 0.95 \rightarrow 0.9$ & 0.2 & 0.5715 & 0.03 & 0.0249 \\
\hline$\chi: 0.25 \rightarrow 0.3$ & 0.2 & 0.3014 & 0.03 & 0.0404 \\
\hline$\lambda: 0.5 \rightarrow 0.55$ & 0.2 & 0.2834 & 0.03 & 0.0416 \\
\hline \multicolumn{5}{|l|}{ Panel C: Proposition 3} \\
\hline$\eta: 0.95 \rightarrow 0.9$ & 0.1798 & 0.2683 & 0.03 & 0.0417 \\
\hline$\chi: 0.25 \rightarrow 0.3$ & 0.1953 & 0.2683 & 0.03 & 0.0422 \\
\hline$\lambda: 0.5 \rightarrow 0.55$ & 0.1979 & 0.2683 & 0.03 & 0.0424 \\
\hline
\end{tabular}

Note: Values in Italics represent the endogenous variables allowed to change in response to higher corruption. 
Table 3

Values of Endogenous Variables under Active Government Policy

\begin{tabular}{|c|c|c|}
\hline Endogenous variables & Value & Definition \\
\hline$r$ & 0.2855 & $\begin{array}{l}\text { Real rate of return on capital } \\
\text { holdings (MPK) }\end{array}$ \\
\hline$b$ & 0.5191 & $\begin{array}{l}\text { Linear output productivity of } \\
\text { private capital }\end{array}$ \\
\hline$\delta$ & 0.2362 & $\begin{array}{l}\text { Fraction of bank deposits lent to } \\
\text { firms }\end{array}$ \\
\hline$R^{*}$ & 0.0388 & $\begin{array}{l}\text { Real rate of return on money } \\
\text { holdings }\end{array}$ \\
\hline$\tau^{*}$ & 0.1005 & Income (wage) tax rate \\
\hline$\theta^{*}$ & 0.2189 & $\begin{array}{l}\text { Proportion of output toward public } \\
\text { goods expenditure }\end{array}$ \\
\hline$\gamma$ & 0.0864 & $\begin{array}{l}\text { Equilibrium growth rate of output } \\
\text { per capita }\end{array}$ \\
\hline
\end{tabular}

Table 4

Comparative Statics Exercises of Active Government Policy

\begin{tabular}{|c|c|c|c|c|}
\hline & $\boldsymbol{\theta}^{*}$ & $\boldsymbol{\tau}^{*}$ & $\boldsymbol{R}^{*}$ & $\gamma$ \\
\hline Benchmark values & 0.2189 & 0.1005 & 0.0388 & 0.0864 \\
\hline \multicolumn{5}{|l|}{ Corruption type } \\
\hline$\eta: 0.95 \rightarrow 0.9$ & 0.1682 & 0.1571 & 0.0371 & 0.0667 \\
\hline$\chi: 0.25 \rightarrow 0.3$ & 0.1383 & 0.6014 & 0.0490 & 0.0288 \\
\hline$\lambda: 0.5 \rightarrow 0.55$ & 0.2178 & 0.1248 & 0.0377 & 0.0839 \\
\hline
\end{tabular}

Note: Values in Italics represent the endogenous variables allowed to change in response to higher corruption. 
